\title{
Review \\ Contamination of Soil, Water, Fresh Produce, and Bivalve Mollusks with Toxoplasma gondii Oocysts: A Systematic Review
}

\author{
Nadia María López Ureña ${ }^{1}$, Umer Chaudhry ${ }^{2}$ (D), Rafael Calero Bernal ${ }^{1}$ (D), Santiago Cano Alsua ${ }^{3}$, \\ Davide Messina $^{2,4}$, Francisco Evangelista ${ }^{2}$, Martha Betson ${ }^{2}$, Marco Lalle ${ }^{5} \mathbb{D}$, Pikka Jokelainen ${ }^{6} \mathbb{D}$, \\ Luis Miguel Ortega Mora ${ }^{1}$ and Gema Álvarez García ${ }^{1, * \mathbb{D}}$
}

Citation: López Ureña, N.M.; Chaudhry, U.; Calero Bernal, R.;

Cano Alsua, S.; Messina, D.;

Evangelista, F.; Betson, M.; Lalle, M.; Jokelainen, P.; Ortega Mora, L.M.; et al. Contamination of Soil, Water, Fresh Produce, and Bivalve Mollusks with Toxoplasma gondii Oocysts: A Systematic Review. Microorganisms 2022, 10, 517. https://doi.org/ 10.3390/microorganisms10030517

Academic Editor: Pat Nuttall

Received: 3 January 2022

Accepted: 25 February 2022

Published: 27 February 2022

Publisher's Note: MDPI stays neutral with regard to jurisdictional claims in published maps and institutional affiliations.

Copyright: () 2022 by the authors. Licensee MDPI, Basel, Switzerland. This article is an open access article distributed under the terms and conditions of the Creative Commons Attribution (CC BY) license (https:/ / creativecommons.org/licenses/by/ $4.0 /)$.
1 SALUVET Research Group, Animal Health Department, Veterinary Faculty, Complutense University of Madrid, 28040 Madrid, Spain; nadiamlo@ucm.es (N.M.L.U.); r.calero@ucm.es (R.C.B.); luis.ortega@ucm.es (L.M.O.M.)

2 Veterinary Epidemiology and Public Health Department, School of Veterinary Medicine, University of Surrey, Guildford GU2 7XH, UK; u.chaudhry@surrey.ac.uk (U.C.); d.messina@surrey.ac.uk or davide.messina1@nottingham.ac.uk (D.M.); f.evangelista@surrey.ac.uk (F.E.); m.betson@surrey.ac.uk (M.B.)

3 Computing Services, Research Support Center, Complutense University of Madrid, 28040 Madrid, Spain; scano@ucm.es

4 Division of Veterinary Clinical Science, School of Veterinary Medicine and Science, University of Nottingham, Sutton Bonington, Loughborough LE12 5RD, UK

5 Unit of Foodborne and Neglected Parasitic Diseases, Department of Infectious Diseases, Istituto Superiore di Sanità, 00161 Roma, Italy; marco.lalle@iss.it

6 Department of Bacteria, Parasites and Fungi, Infectious Disease Preparedness, Statens Serum Institute, University of Copenhagen, 2300 Copenhagen, Denmark; pijo@ssi.dk

* Correspondence: gemaga@ucm.es; Tel.: +34-913944095

\begin{abstract}
Toxoplasma gondii is a major foodborne pathogen capable of infecting all warm-blooded animals, including humans. Although oocyst-associated toxoplasmosis outbreaks have been documented, the relevance of the environmental transmission route remains poorly investigated. Thus, we carried out an extensive systematic review on T. gondii oocyst contamination of soil, water, fresh produce, and mollusk bivalves, following the PRISMA guidelines. Studies published up to the end of 2020 were searched for in public databases and screened. The reference sections of the selected articles were examined to identify additional studies. A total of 102 out of 3201 articles were selected: 34 articles focused on soil, 40 focused on water, 23 focused on fresh produce (vegetables/fruits), and 21 focused on bivalve mollusks. Toxoplasma gondii oocysts were found in all matrices worldwide, with detection rates ranging from $0.09 \%(1 / 1109)$ to $100 \%(8 / 8)$ using bioassay or PCR-based detection methods. There was a high heterogeneity $\left(\mathrm{I}^{2}=98.9 \%\right)$, which was influenced by both the sampling strategy (e.g., sampling site and sample type, sample composition, sample origin, season, number of samples, cat presence) and methodology (recovery and detection methods). Harmonized approaches are needed for the detection of $T$. gondii in different environmental matrices in order to obtain robust and comparable results.
\end{abstract}

Keywords: Toxoplasma gondii; oocysts; environment; soil; water; fresh produce; fruit; bivalve mollusk; sampling strategy; methodology

\section{Introduction}

Toxoplasmosis is one of the most important opportunistic parasitic diseases affecting humans and animals worldwide and is caused by the obligate intracellular protist Toxoplasma gondii. Clinical manifestations associated with toxoplasmosis are various, and they include ocular disease [1,2], pneumonia [3,4], and encephalitis in immunocompromised patients [1,5]. Toxoplasma gondii infection can also cause spontaneous abortion, congenital malformations, and stillbirth in both humans and animals [6,7]. 
Domestic and wild felids are the specific definitive hosts of T. gondii, whereas warmblooded vertebrates, including humans, are intermediate hosts [8]. Up to $70 \%$ of the cat population is infected with T. gondii [9], and the infected cats can shed millions of oocysts in their feces. The subsequent development of sporulated oocysts in the environment depends on temperature and humidity $[10,11]$.

Humans, as well as animals, can become infected with T. gondii through the consumption of raw or undercooked meat of infected animals harboring the tissue-dwelling stages of the parasite (bradyzoites contained within tissue cysts) [12] as well as via congenital transmission and blood transfusion by the active replicative stages of the parasite (tachyzoites) [10]. Another important route of human and animal infection is through the ingestion of sporulated T. gondii oocysts present in the environment, contaminating soil, water, and feed and food, including fresh produce and seafood [13]. According to a systematic review of studies carried out up to March 2018,44.1\% (15/34) of documented worldwide outbreaks were oocyst-related [14].

Soil contamination is a significant source of human infection, with soil of public parks, schools, gardens, and farms considered particularly important. Oocysts can be distributed within the soil by arthropods, earthworms, wind, and rain [7], and the sporulated oocysts are highly resistant and can persist infective in soil for up to two years [11].

Waterborne infections associated with $T$. gondii oocysts are nowadays considered increasingly significant due to evidence of large-scale outbreaks $[7,13]$. Water in irrigation systems, rivers, lakes, beaches, and coasts, as well as wastewater and groundwater can be contaminated with the environmentally resistant oocysts. Moreover, oocysts can survive various inactivation procedures using chemical reagents, including sodium hypochlorite and chlorine $[15,16]$. Oocysts remain viable in water for 18 months at $4{ }^{\circ} \mathrm{C}$ after exposure to $2 \%$ sulfuric acid [7,17], for 15 and 54 months at $20-25^{\circ} \mathrm{C}$ and $4{ }^{\circ} \mathrm{C}$ in fresh water, respectively, and around 6 months in artificial seawater $(15 \mathrm{ppt})$ at the same temperatures [18].

In recent years, T. gondii infection cases linked to fresh vegetable consumption have been on the increase [14]. Oocyst contamination of fresh vegetables may occur through cultivation in contaminated soil or using contaminated water for irrigation or washing. As testing for parasite contamination in fresh produce is neither regulated nor mandatory, the increased popularity of consumption of raw and ready-to-eat vegetables may pose a new potential risk for consumers who could be accidentally exposed to oocysts, since most post-harvest processing measures do not guarantee the complete removal of oocysts or their effective inactivation [16,19].

Toxoplasma gondii oocysts can also enter the marine environment through improper disposal of sewage, inefficient treatment plants, water discharge, and water runoff [20], and they can cause infections in marine animals and the contamination of marine fauna [21,22]. Consistently, oocysts have been detected in wild and commercial bivalve mollusks in several countries. Bivalves continuously filter large volumes of water and concentrate microorganisms [23]. They can retain viable T. gondii oocysts for 85 days following uptake [24]. Thus, they are considered good biological indicators of parasitic contamination of aquatic environments and could pose another risk for consumers when consumed undercooked or raw $[18,25]$.

Environmental contamination with $T$. gondii oocysts is understudied and likely underestimated, which is partly due to the lack of suitable harmonized sampling approaches and detection methods. Studies on cat feces or susceptible intermediate hosts have been used as a substitute to predict the level of environmental contamination [26,27], but they may have inadequate power to accurately assess contamination. Due to limited baseline data on oocyst occurrence in environmental samples, accurate estimation of the contamination in the environment requires large sample sizes and sample volumes, which may contain small quantities of oocysts of different ages [7]. Limitations in oocyst recovery and detection methods, in combination with various sampling strategies, have made it difficult to ascertain the contribution of environmental contamination with T. gondii oocysts to human infections. Indirect methods for discriminating between infections caused by 
oocysts vs. tissue-dwelling stages of T. gondii have been developed but have not been widely applied [28].

Another important challenge to full evaluation of the relevance of T. gondii oocyst infection route is the assessment and quantification of oocyst viability and therefore infectivity for humans and animals. So far, the only reliable method is based on mouse bioassay, i.e., experimental administration of oocysts to mice and detection of infection in tissues [8], although new approaches based on molecular methods have been proposed and are under evaluation for their applicability [29-31].

To date, reviews on T. gondii environmental contamination of one [18,32] or more matrices [7], and systematic reviews covering one matrix exist [9,33-35]; however, they mainly focused on detection rates or analytical methods. Thus, this article aims to provide a more complete, comprehensive systematic review of the existing literature on environmental contamination with $T$. gondii oocysts, including available data on sampling strategies, and identifying relevant knowledge gaps and limitations in relation to sampling strategies and methods for the recovery and detection of T. gondii oocysts in soil, water, fresh produce, and bivalve mollusks. Finally, based on the observations, recommendations are suggested for future studies on environmental contamination with $T$. gondii oocysts.

\section{Materials and Methods}

\subsection{Literature Search and Eligibility Criteria}

A systematic review of the prevalence of T. gondii oocysts in soil, water, fresh produce (vegetables and fruits), and bivalve mollusks worldwide was performed; all papers published, with no restriction on language, until the end of 2020 were included, following the Preferred Reporting Items for Systematic Reviews and Meta-Analyses (PRISMA) [36].

The databases used were PubMed, Web of Science, and Scopus. In all cases, a combination of three search terms was employed and included "Toxoplasma" and "oocysts" or "oocyst" and "vegetables" or "fruits" or "ready to eat" or "salads" or "greenery" or "water" or "soil" or "bivalves" or "mussels" or "clams" or "oysters" or "abalone". In view of the diversity of terms yielding eligible studies, an additional search was performed using related terms such as "food" or "products" or "otters". Additionally, the bibliographies of the selected articles were screened to identify studies to include (Supplementary Table S1).

The articles were selected using the following inclusion criteria: worldwide studies reporting direct detection of $T$. gondii oocysts in one of the matrices of interest (soil, water, fresh produce, and bivalves) with full text available. Exclusion criteria were the following: methodological studies aiming only to the development or improvement of oocyst recovery or detection methods (i.e., using artificial spiking of matrices), studies performed on other matrices, studies without available full text, studies published after 2020, and duplicates.

\subsection{Selection Process and Data Extraction}

Three investigators carried out the initial screening focusing on title and abstract, and based on this, eligible articles were preselected and subjected to an in-depth review to confirm if they met the selection criteria. Subsequently, data extraction was carried out by two co-authors, and a third co-author resolved discrepancies.

For data extraction, one data sheet per matrix was created in Microsoft Excel 2013. For all matrices, the data sheet included sample type/details and origin, sampling year and season, period, country and continent, samples by categories $(n)$, total number of samples, sample units, presence of cats in the sampling area, association with human T. gondii infection or toxoplasmosis (outbreaks or sporadic cases), positive samples by categories (number and percentage), total number of positive samples (number and percentage), sample collection and preparation, oocyst recovery and detection methods, DNA extraction method and molecular markers used, oocyst quantification (mean, median, and range), analytical sensitivity (Se), additional molecular methods used, source of information, journal subject area, and other parasites investigated (Supplementary Tables S2-S5). 
Specific columns were also included in the spreadsheets according to the type of matrix. For soil, there were columns related to sampling site, sample size, and depth of sample collection $(\mathrm{cm})$. Columns related to the type of aquifer, the uses, and the treatment received were added for water, and matrix composition, product type (organic, conventional or both), and product presentation (bulk, packaged, or ready-to-eat (RTE)) for fresh produce. Finally, for bivalves, columns related to sampled species, sampling site, specimen length $(\mathrm{cm})$, depth of collection $(\mathrm{cm})$, and type of tissue or material analyzed were added.

When a study analyzed two or more matrices, data were extracted and considered separately for each matrix. The data extracted were limited to the information provided in the articles.

\subsection{Data Analyses}

Several studies reported oocyst detection by light microscopy or direct visualization of $T$. gondii oocysts by autofluorescence using an epifluorescent microscope as the only or initial screening method. However, since these techniques cannot prove the identity of T. gondii oocysts due to their shape and size similarity with several genera and species of the Sarcocystidae family, and because oocyst wall autofluorescence is not an exclusive feature of T. gondii, data based on microscopy findings were extracted and included in Supplementary Tables S2-S5, but they were not considered for data analyses. Accordingly, only data based on molecular and bioassay methods were included in the Results and Discussion sections. Moreover, only data from individual experimental samples were included in the analysis, not data from pooled samples. Regarding fresh produce, it was not always clear whether pooled samples were analyzed. Thus, if the mass of the sample analyzed was greater than the sample unit mass, it was considered to be a pool and was consequently excluded (e.g., sample units of $3600 \mathrm{~g}$ of lettuce [37] or $1000 \mathrm{~g}$ of strawberries [38]).

For the evaluation of heterogeneity and pooled estimates, detection rates reported in each study were combined per matrix (soil, water, fresh produce, bivalve mollusks), using STATA 15.0 software (StataCorp, Bryan, TX, USA) and a restricted maximum likelihood method with a random effects model. A Forest plot was created for easy data deviation within matrix type (Supplementary Figures S1-S4). The inverse variance index $\left(\mathrm{I}^{2}\right)$ was used to quantify heterogeneity $[39,40]$. In addition, study bias and heterogeneities at the study level were calculated by Egger's test, funnel plots (Supplementary Figure S5), and Cochran's $Q$ test, respectively [41].

\section{Results and Discussion}

\subsection{Literature Search and Article Selection}

A total of 3201 articles were obtained from the search process, and 321 were preselected based on their titles or abstract and removal of duplicates. Finally, 102 articles were included for data extraction (Figure 1; Supplementary Table S1). Among them, 13 articles focused on the analysis of two or more matrices and 34 articles reported data on soil, 40 reported data on water, 23 reported data on fresh produce (vegetables and fruit), and 21 reported data on bivalve mollusks. An attempt to gather more data on T. gondii oocyst prevalence was undertaken by collecting gray literature (e.g., unpublished scientific information, including reports from governmental agencies, thesis dissertations, conference proceedings) using an online survey administered to experts in the field. The search yielded seven reports not published in English-language peer-reviewed journals with very limited information on the sampling strategies and methodologies employed [42]. 


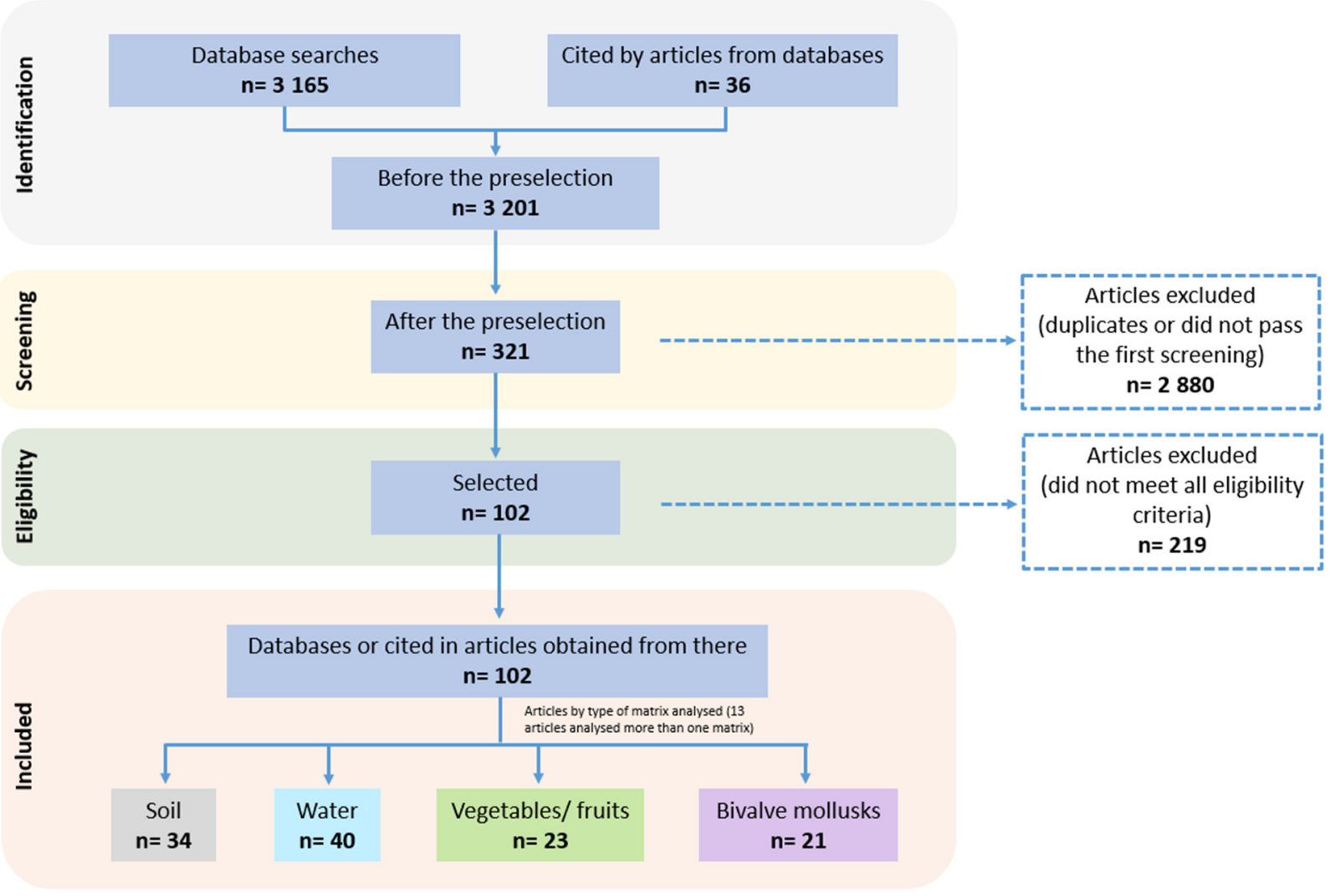

Figure 1. Four-step flow diagram of the systematic review of the presence of Toxoplasma gondii oocysts in soil, water, vegetables, fruit, and bivalve mollusks worldwide until the end of 2020.

\subsection{Toxoplasma gondii Oocyst Detection in Environmental Matrices}

Different environmental matrices have received increasing attention over the past 50 years. The studies included were conducted on soil $(n=34)$ between 1971 and 2019, water $(n=40)$ between 1992 and 2019, fresh produce $(n=23)$ between 2006 and 2019, and bivalves $(n=21)$ between 2002 and 2018. Soil was first investigated early in the 1970s immediately after the full life cycle of $T$. gondii was described and the environmentally resistant stage, the oocyst, was discovered [43]. Later, in the 1990s, the first reports of the presence of T. gondii in water were published. More recently, in the 2000s, studies have been conducted in bivalve mollusks and fresh produce.

The timeline of the studies included here appears to be in accordance with our increased understanding of the importance of other food and waterborne zoonotic protists (particularly Cryptosporidium spp., but also Giardia duodenalis and Cyclospora cayetanensis) and the detection of outbreaks. Indeed, from the 1990s onwards, numerous studies demonstrated the presence of Cryptosporidium spp. in public water supplies and recreational and river water sources [44], together with two massive outbreaks of cryptosporidiosis in humans associated with water supplies in Georgia and Milwaukee in the United States [45,46], among others. Moreover, water-related toxoplasmosis outbreaks were documented earlier than fresh produce-related outbreaks [14]. Finally, the first studies conducted on mollusks and fresh produce from 2002 or 2006 onwards coincide with similar investigations carried out in other food and waterborne protists. Late in the 1990s, it was reported that bivalves could act as mechanical vectors of Cryptosporidium spp. oocysts due to their survival in estuarine waters for several weeks [47], which led to further studies on different bivalve species. Since 2000, both Cryptosporidium spp. and T. gondii have been more extensively studied in fresh vegetables and fruit [33]. A recent review stated that $5.9 \%(2 / 34)$ of oocystrelated outbreaks were attributable to fresh produce consumption, with both types of fresh produce, vegetables and fruit, as sources of oocysts in outbreaks occurring since 2009 [14]. 
Toxoplasma gondii was detected in different environmental matrices worldwide using molecular methods (e.g., PCR and loop-mediated isothermal AMPlification, LAMP) or bioassays, which are sensitive and specific methods, as shown in Tables 1-4 and Figure 2.

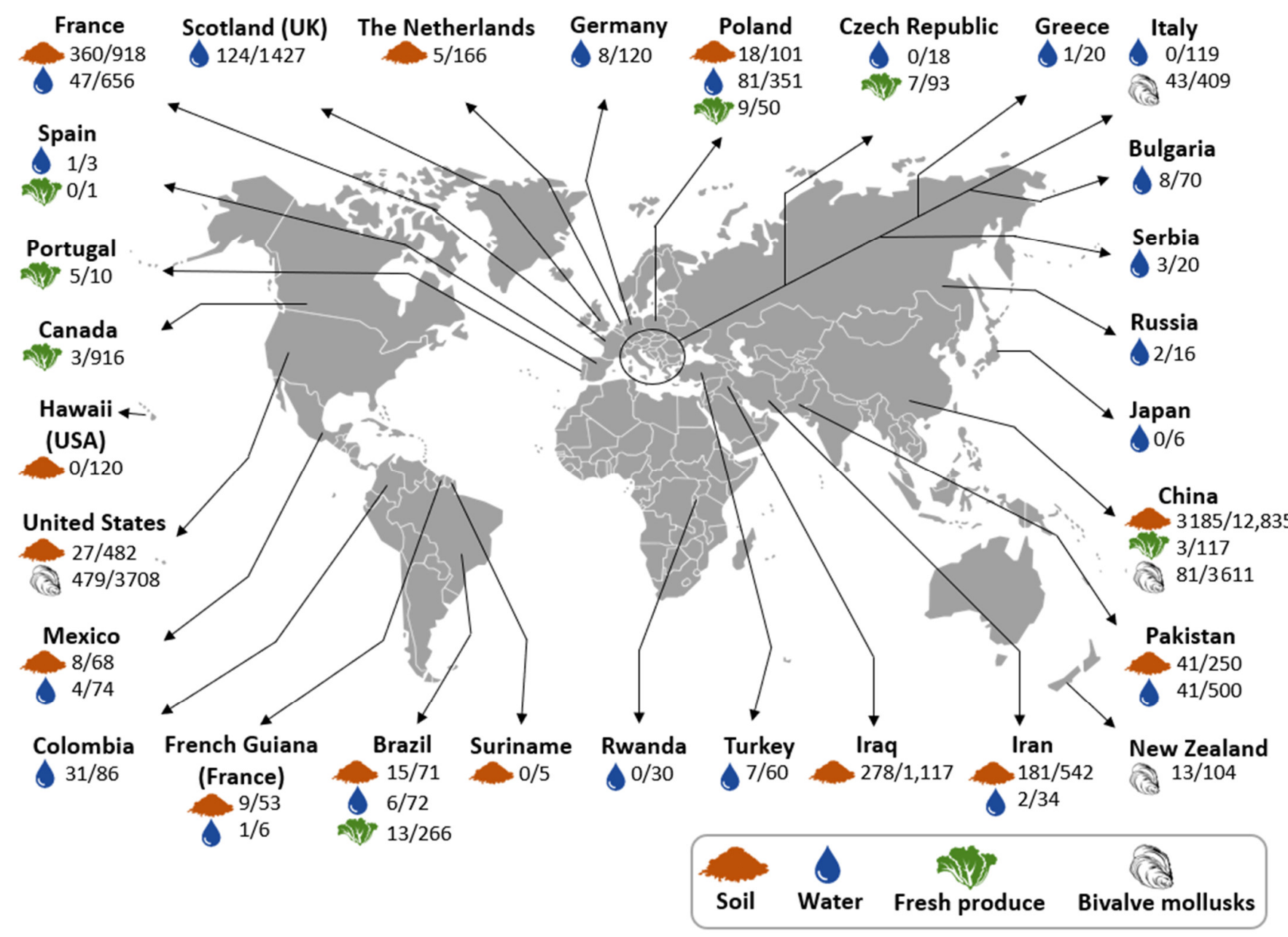

Figure 2. Worldwide detection of Toxoplasma gondii oocysts in environmental matrices based on molecular methods (PCR, qPCR, and LAMP) in studies published by the end of 2020. Results are presented as positive samples/total of samples collected. Articles that analyzed pooled samples and did not specify how the number of positive individual samples was estimated were excluded.

The presence of T. gondii oocysts in soil was detected in 28 out of 34 studies in the following countries: Brazil $(n=5)$, China $(n=7)$, Costa Rica $(n=1)$, France $(n=3)$, French Guiana $(n=1)$, Iran $(n=3)$, Iraq $(n=1)$, Mexico $(n=1)$, Panama $(n=1)$, Pakistan $(n=1)$, Poland $(n=1)$, the Netherlands $(n=1)$, and the United States $(n=2)$ with overall detection rates ranging from $1.0 \%(7 / 700)$ [48] to $100 \%$ (5/5) [49], both from China (Table 1 and Figure 2; Supplementary Table S2).

Water was the environmental matrix most extensively studied worldwide with 25 out of 40 articles reporting T. gondii-positive samples in Brazil $(n=6)$, Colombia $(n=2)$, Egypt $(n=1)$, France $(n=2)$, French Guiana (France) $(n=1)$, Germany $(n=1)$, Greece and Bulgaria $(n=1)$, Iran $(n=1)$, Mexico $(n=1)$, Pakistan $(n=1)$, Poland $(n=3)$, Russia and Bulgaria $(n=1)$, Scotland $(n=1)$, Serbia $(n=1)$, Spain $(n=1)$, and Turkey $(n=1)$. Overall, detection rates ranged from 5\% (1/20) in Greece [50] to 100\% (8/8) in Brazil [51], and most studies reported a detection rate below 20\% (Table 2 and Figure 2; Supplementary Table S3). 
Altogether, twenty-three studies were conducted on fresh produce matrices that were classified as leafy greens, non-leafy vegetables (including root crops), herbs, and fruit. Positive samples were reported in all fresh produce matrices in 13 articles from Brazil $(n=2)$, Canada $(n=1)$, China $(n=1)$, Colombia $(n=2)$, the Czech Republic $(n=1)$, Egypt $(n=1)$, Italy $(n=1)$, Pakistan $(n=1)$, Poland $(n=1)$, Spain and Portugal $(n=1)$, and Switzerland $(n=1)$ (Table 3 and Figure 2). Detection rates in fresh produce ranged from $0.3 \%$ (3/1171) in Canada [52] to 50.0\% (13/26) in Portugal [37], and in the majority of studies, detection rates were below 10\% (Table 3 and Figure 2, Supplementary Table S4).

Finally, the presence of T. gondii oocysts in bivalves was reported in 19 out of 22 studies in Brazil $(n=4)$, China $(n=2)$, France $(n=1)$, Italy $(n=3)$, New Zealand $(n=1)$, Tunisia $(n=1)$, Turkey $(n=2)$, and the United States $(n=5)$, with detection rates that varied from $0.1 \%(1 / 1109)$ [21] to $46.3 \%(19 / 41)$ [53], both in the United States, and from $1.3 \%(2 / 160)$ to $31.0 \%(19 / 60)$ in pooled samples from Brazil [54] and the United States [55], respectively. In most studies, the detection rates were below 7\% (Table 4 and Figure 2, Supplementary Table S5). 
Table 1. Worldwide detection of Toxoplasma gondii oocysts in soil based on molecular and bioassay methods in articles published up to the end of 2020.

\begin{tabular}{|c|c|c|c|c|c|c|c|c|c|}
\hline \multicolumn{6}{|c|}{ Sampling Strategy } & \multicolumn{2}{|c|}{ Methods Used } & \multirow{2}{*}{$\begin{array}{c}\text { Results } \\
\begin{array}{c}\text { Positive Samples } \\
(\%)\end{array}\end{array}$} & \multirow[t]{2}{*}{ Sources } \\
\hline $\begin{array}{l}\text { Sampling } \\
\text { Location } \\
\text { (Country) }\end{array}$ & Sample Origin & $\begin{array}{l}\text { No. of Samples } \\
\text { Collected }\end{array}$ & $\begin{array}{l}\text { Sample Amount } \\
\text { Collected/Sample } \\
\text { Size Analyzed } \\
\text { (Depth) }\end{array}$ & $\begin{array}{l}\text { Presence of } \\
\quad \text { Cats }\end{array}$ & $\begin{array}{l}\text { Link with Human } \\
\text { Toxoplasmosis }{ }^{a}\end{array}$ & $\begin{array}{l}\text { Oocyst Recovery } \\
\text { Method }^{\dagger}\end{array}$ & $\begin{array}{l}\text { Detection Methods (Molecular } \\
\text { Target) }\end{array}$ & & \\
\hline Brazil & $\begin{array}{l}\text { Paddocks from ostrich } \\
\text { farms }\end{array}$ & 40 & $250 \mathrm{~g} / 25 \mathrm{~g}(5-10 \mathrm{~cm})$ & No data * & No & $\begin{array}{l}\text { Wash, filtration, } \\
\text { centrifugation, flotation, } \\
\text { centrifugation, wash, and } \\
\text { centrifugation }\end{array}$ & $\begin{array}{l}\text { PCR, qPCR ( } 529 \text { RE and } 18 \mathrm{~S} \\
\text { rRNA) }\end{array}$ & $13(32.5)^{b}$ & [57] \\
\hline Brazil & $\begin{array}{l}\text { Elementary public } \\
\text { schools }\end{array}$ & 31 & $\begin{array}{l}1000 \mathrm{~g} / \text { no data } \\
(5 \mathrm{~cm})\end{array}$ & No data & No & $\begin{array}{l}\text { Flotation and } \\
\text { centrifugation }\end{array}$ & $\begin{array}{l}\text { Mouse bioassay: squash } \\
\text { Mouse bioassay: histopathology } \\
\text { Mouse bioassay: } \\
\text { immunohistochemistry } \\
\text { Mouse bioassay: indirect } \\
\text { fluorescent antibody test (IFAT) }\end{array}$ & $\begin{array}{l}7(22.6) \\
0 \\
10(32.3) \\
8(25.8)\end{array}$ & [58] \\
\hline Brazil & Sheep farms & $\begin{array}{l}10 \text {, each inoculated } \\
\text { in } 5 \text { mice }\end{array}$ & $1 \mathrm{~g} / 1 \mathrm{~g}$ (no data) & Yes & No & $\begin{array}{l}\text { Wash, flotation, and } \\
\text { centrifugation }\end{array}$ & $\begin{array}{l}\text { PCR }(529 \text { RE) } \\
\text { Mouse bioassay IP/PO- PCR } \\
\text { (529 RE) } \\
\text { Mouse bioassay IP/PO- IFAT }\end{array}$ & $\begin{array}{l}0 \\
\text { IP: } 6 \text { (30.0), PO: } 7 \\
(23.3) \\
\text { IP: } 14 \text { (70.0), PO: } 19 \\
\text { (63.3) }\end{array}$ & [59] \\
\hline Brazil & $\begin{array}{l}\text { Horticultural } \\
\text { properties }\end{array}$ & 10 & $\begin{array}{l}10 \mathrm{~g} / 10 \mathrm{~g} \text { (from } \\
\text { surface) }\end{array}$ & Yes & No & Wash and centrifugation & PCR (529 RE) & $2(20)^{b}$ & [61] \\
\hline China & $\begin{array}{l}\text { Schools, parks, farms, } \\
\text { and coastal beaches }\end{array}$ & 2100 & $20 \mathrm{~g} /$ no data $(5 \mathrm{~cm})$ & No data & No & $\begin{array}{l}\text { Wash, flotation, } \\
\text { centrifugation, wash, and } \\
\text { centrifugation }\end{array}$ & $\begin{array}{l}\text { PCR, Semi-nPCR, nPCR } \\
\text { (529 RE, B1, and ITS-1) }\end{array}$ & $230(10.9)^{d}$ & [62] \\
\hline China & Public parks & 252 & No data $/ 0.5 \mathrm{~g}(5 \mathrm{~cm})$ & Yes & No & No data & $\begin{array}{l}\text { PCR (B1 and 529 RE) } \\
\text { LAMP (MIC3, F3, B3, BIP, FIP, } \\
\text { LD, BF) }\end{array}$ & $\begin{array}{l}41(16.3)^{\mathrm{d}} \\
58(23.0)\end{array}$ & [63] \\
\hline China & Pig farms & 95 & No data $/ 0.5 \mathrm{~g}(5 \mathrm{~cm})$ & Yes & No & No data & $\begin{array}{l}\text { PCR (B1 and } 529 \text { RE) } \\
\text { LAMP (MIC3, F3, B3, BIP, FIP, } \\
\text { LD, BF) }\end{array}$ & $\begin{array}{l}20(21.1) \\
36(37.9)\end{array}$ & [64] \\
\hline China & $\begin{array}{l}\text { Urban areas (foci of } \\
\text { human } \\
\text { habitation, gravel, } \\
\text { sand, industrial and } \\
\text { commercial land, } \\
\text { woodland, grassland) }\end{array}$ & 9420 & $\begin{array}{l}20 \mathrm{~g} / 4 \text { replicates of } \\
5 \mathrm{~g}(10 \mathrm{~cm})\end{array}$ & Yes & No & $\begin{array}{l}\text { Wash, flotation, } \\
\text { centrifugation, wash, and } \\
\text { centrifugation }\end{array}$ & qPCR (529 RE) & $2853(30.3)$ & {$[65]$} \\
\hline
\end{tabular}


Table 1. Cont.

\begin{tabular}{|c|c|c|c|c|c|c|c|c|c|}
\hline \multicolumn{6}{|c|}{ Sampling Strategy } & \multicolumn{2}{|c|}{ Methods Used } & Results & \multirow[t]{2}{*}{ Source } \\
\hline $\begin{array}{l}\text { Sampling } \\
\text { Location } \\
\text { (Country) }\end{array}$ & Sample Origin & $\begin{array}{l}\text { No. of Samples } \\
\text { Collected }\end{array}$ & $\begin{array}{l}\text { Sample Amount } \\
\text { Collected/Sample } \\
\text { Size Analyzed } \\
\text { (Depth) }\end{array}$ & $\begin{array}{l}\text { Presence of } \\
\text { Cats }\end{array}$ & $\begin{array}{l}\text { Link with Human } \\
\text { Toxoplasmosis }^{a}\end{array}$ & $\begin{array}{l}\text { Oocyst Recovery } \\
\text { Method }^{+}\end{array}$ & $\begin{array}{l}\text { Detection Methods (Molecular } \\
\text { Target) }\end{array}$ & $\begin{array}{l}\text { Positive Samples } \\
\text { (\%) }\end{array}$ & \\
\hline China & $\begin{array}{l}\text { Schools, parks, } \\
\text { and grazing area }\end{array}$ & 268 & $\begin{array}{l}\text { No data } / 5 \mathrm{~g} \\
\text { (no data) }\end{array}$ & No data & No & $\begin{array}{l}\text { Wash, filtration, } \\
\text { centrifugation, flotation, } \\
\text { wash, and centrifugation, } \\
\text { presumably }\end{array}$ & Semi-nested PCR (529 RE) & $34(12.7)^{d}$ & [66] \\
\hline Costa Rica & $\begin{array}{l}\text { Yard and coffee } \\
\text { plantation }\end{array}$ & 15 & $\begin{array}{l}10 \mathrm{~g} / 10 \mathrm{~g}(\text { from } \\
\text { surface or } 5-7 \mathrm{~cm})\end{array}$ & Yes & No & $\begin{array}{l}\text { Wash, centrifugation, } \\
\text { flotation, centrifugation }\end{array}$ & $\begin{array}{l}\text { Mouse bioassay: Dye test and } \\
\text { squash }\end{array}$ & $4(26.7)^{\mathrm{b}}$ & [67] \\
\hline France & $\begin{array}{l}\text { Areas around a } \\
\text { hospital where cats } \\
\text { defecate }\end{array}$ & 117 & $\begin{array}{l}200-300 \mathrm{~g} / 10 \mathrm{~g} \\
(2 \mathrm{~cm})\end{array}$ & Yes & No & $\begin{array}{l}\text { Wash, filtration, } \\
\text { centrifugation, flotation, } \\
\text { and centrifugation }\end{array}$ & qPCR (529 RE) & $11(9.4)^{b}$ & [68] \\
\hline France & $\begin{array}{l}\text { Village areas, crop } \\
\text { field, grassland, forest }\end{array}$ & 243 & $\begin{array}{l}20 \mathrm{~g} / 4 \text { replicates of } \\
5 \mathrm{~g} \text { (up to } 2 \mathrm{~cm} \text { ) }\end{array}$ & Yes & No & $\begin{array}{l}\text { Wash, flotation, } \\
\text { centrifugation, wash, and } \\
\text { centrifugation }\end{array}$ & qPCR (529 RE) & $71(29.2)$ & [69] \\
\hline $\begin{array}{l}\text { French Guiana } \\
\text { (France) }\end{array}$ & $\begin{array}{l}\text { Areas around houses } \\
\text { and random sites }\end{array}$ & 53 & $\begin{array}{l}\text { No data } / 20 \mathrm{~g} \\
\text { (no data) }\end{array}$ & Yes & Yes & Wash and centrifugation & PCR (529 RE) & $9(17.0)^{b, d}$ & [70] \\
\hline Hawaii (USA) & $\begin{array}{l}\text { University campus and } \\
\text { a natural area reserve }\end{array}$ & 120 & $\begin{array}{l}\text { No data } / 20 \mathrm{~g} \\
(10 \mathrm{~cm})\end{array}$ & Yes & No & $\begin{array}{l}\text { Wash, centrifugation, } \\
\text { flotation, centrifugation, } \\
\text { wash, and centrifugation }\end{array}$ & PCR (GRA6) & 0 & [71] \\
\hline Iran & Urban and rural areas & 192 & $\begin{array}{l}300-500 \mathrm{~g} / 7 \mathrm{~g} \\
\text { (no data) }\end{array}$ & Yes & No & $\begin{array}{l}\text { Wash, centrifugation, } \\
\text { flotation, centrifugation, } \\
\text { wash, and centrifugation }\end{array}$ & nPCR (529 RE) & $150(78.1)$ & [72] \\
\hline Iran & $\begin{array}{l}\text { Sand pits, playgrounds, } \\
\text { public parks, and areas } \\
\text { around rubbish dumps }\end{array}$ & 200 & $400 \mathrm{~g} / 40 \mathrm{~g}(2-5 \mathrm{~cm})$ & Yes & No & $\begin{array}{l}\text { Wash, filtration, } \\
\text { centrifugation, flotation, } \\
\text { and centrifugation }\end{array}$ & PCR (GRA6) & $18(9)^{d}$ & [73] \\
\hline Iran & $\begin{array}{l}\text { Rubbish dumps, } \\
\text { children's playground, } \\
\text { parks and public places }\end{array}$ & 150 & $300 \mathrm{~g} /$ no data $(3 \mathrm{~cm})$ & No data & No & $\begin{array}{l}\text { Wash, centrifugation, } \\
\text { flotation, and } \\
\text { centrifugation }\end{array}$ & PCR (B1) & $13(8.7)^{\mathrm{d}}$ & [74] \\
\hline
\end{tabular}


Table 1. Cont.

\begin{tabular}{|c|c|c|c|c|c|c|c|c|c|}
\hline \multicolumn{6}{|c|}{ Sampling Strategy } & \multicolumn{2}{|c|}{ Methods Used } & Results & \multirow[t]{2}{*}{ Sources } \\
\hline $\begin{array}{l}\text { Sampling } \\
\text { Location } \\
\text { (Country) }\end{array}$ & Sample Origin & $\begin{array}{l}\text { No. of Samples } \\
\text { Collected }\end{array}$ & $\begin{array}{c}\text { Sample Amount } \\
\text { Collected/Sample } \\
\text { Size Analyzed } \\
\text { (Depth) }\end{array}$ & $\begin{array}{l}\text { Presence of } \\
\text { Cats }\end{array}$ & $\begin{array}{l}\text { Link with Human } \\
\text { Toxoplasmosis }^{a}\end{array}$ & $\begin{array}{l}\text { Oocyst Recovery } \\
\text { Method }^{+}\end{array}$ & $\begin{array}{l}\text { Detection Methods (Molecular } \\
\text { Target) }\end{array}$ & $\begin{array}{l}\text { Positive Samples } \\
\text { (\%) }\end{array}$ & \\
\hline Mexico & Playground boxes & 68 & $\begin{array}{l}10 \mathrm{~g} / 10 \mathrm{~g}(<2 \mathrm{~cm}, \\
2-10 \mathrm{~cm} \text { or until } \\
\text { reaching rock } \\
\text { bottom) }\end{array}$ & Yes & No & $\begin{array}{l}\text { Wash, centrifugation, } \\
\text { flotation, wash, and } \\
\text { centrifugation }\end{array}$ & nPCR (SAG1) & $8(11.8)$ & [76] \\
\hline Panama & $\begin{array}{l}\text { Outdoor children's } \\
\text { play areas }\end{array}$ & 924 & $30 \mathrm{~g} / 30 \mathrm{~g}$ (no data) & Yes & Yes & $\begin{array}{l}\text { Wash, centrifugation, } \\
\text { flotation, and } \\
\text { centrifugation }\end{array}$ & $\begin{array}{l}\text { Mouse bioassay: direct } \\
\text { agglutination test }\end{array}$ & $10(1.1)$ & [77] \\
\hline Pakistan & $\begin{array}{l}\text { Homes, gardens, } \\
\text { public enclosures, and } \\
\text { backyards from urban } \\
\text { and rural areas }\end{array}$ & $250^{c}$ & $\begin{array}{l}300 \mathrm{~g} / \text { no data } \\
(2-5 \mathrm{~cm})\end{array}$ & Yes & No & No data & PCR (B1, 529 RE) & $\begin{array}{l}\mathrm{B} 1=41(16.4)^{\mathrm{b}} \\
529 \mathrm{RE}=41(16.4)^{\mathrm{b}}\end{array}$ & [78] \\
\hline Poland & $\begin{array}{l}\text { Sand pits, rubbish } \\
\text { dumps and sand heaps }\end{array}$ & 101 & $300 \mathrm{~g} / 40 \mathrm{~g}(2-5 \mathrm{~cm})$ & Yes & No & $\begin{array}{l}\text { Wash, centrifugation, } \\
\text { flotation with } \\
\text { centrifugation, } \\
\text { attachment to a glass } \\
\text { slide and wash of } \\
\text { the glass slide }\end{array}$ & PCR (B1 and 200-300 REP) & $18(17.8)^{\mathrm{d}}$ & [79] \\
\hline Suriname & $\begin{array}{l}\text { Different areas from a } \\
\text { village }\end{array}$ & 5 & $200 \mathrm{~g} / 50 \mathrm{~g}$ (no data) & Yes & Yes & $\begin{array}{l}\text { Flotation (no more } \\
\text { information is given) }\end{array}$ & qPCR (B1) & 0 & [80] \\
\hline $\begin{array}{l}\text { The } \\
\text { Netherlands }\end{array}$ & $\begin{array}{l}\text { Residential gardens } \\
\text { and a limited number } \\
\text { of playgrounds }\end{array}$ & $166^{\mathrm{e}}$ & $100 \mathrm{~g} / 25 \mathrm{~g} \mathrm{(5 \textrm {cm } )}$ & No data & No & Magnetic capture & qPCR (529 RE) & $5(3.0)$ & [81] \\
\hline $\begin{array}{l}\text { The United } \\
\text { States }\end{array}$ & $\begin{array}{l}\text { Cities, state parks, } \\
\text { public playgrounds, } \\
\text { and } \\
\text { community gardens }\end{array}$ & $482^{\mathrm{f}}$ & $\begin{array}{l}20-50 \mathrm{~g} / \text { replicates } \\
\text { of } 5 \mathrm{~g}(2-5 \mathrm{~cm})\end{array}$ & Yes & No & $\begin{array}{l}\text { Wash, flotation, } \\
\text { centrifugation, wash, and } \\
\text { centrifugation }\end{array}$ & nPCR (ITS1) & $27(5.6)^{d}$ & [82] \\
\hline
\end{tabular}


Table 1. Cont.

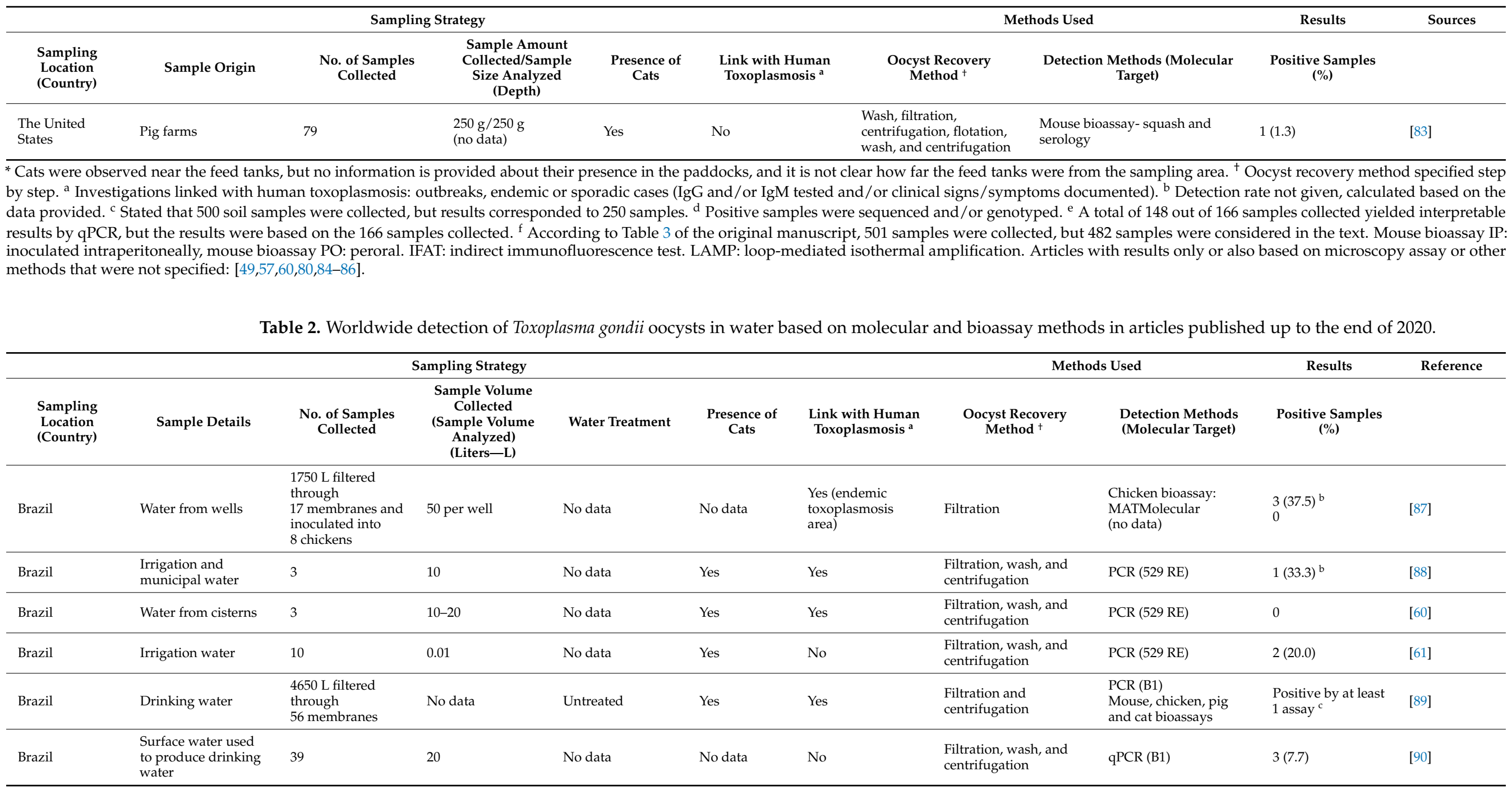


Table 2. Cont.

\begin{tabular}{|c|c|c|c|c|c|c|c|c|c|c|}
\hline \multicolumn{7}{|c|}{ Sampling Strategy } & \multicolumn{2}{|c|}{ Methods Used } & \multirow{2}{*}{$\begin{array}{c}\text { Results } \\
\begin{array}{c}\text { Positive Samples } \\
(\%)\end{array}\end{array}$} & \multirow[t]{2}{*}{ Reference } \\
\hline $\begin{array}{l}\text { Sampling } \\
\text { Location } \\
\text { (Country) }\end{array}$ & Sample Details & $\begin{array}{l}\text { No. of Samples } \\
\text { Collected }\end{array}$ & $\begin{array}{l}\text { Sample Volume } \\
\text { Collected } \\
\text { (Sample Volume } \\
\text { Analyzed) } \\
\text { (Liters-L) }\end{array}$ & Water Treatment & $\begin{array}{l}\text { Presence of } \\
\text { Cats }\end{array}$ & $\begin{array}{l}\text { Link with Human } \\
\text { Toxoplasmosis }{ }^{a}\end{array}$ & $\begin{array}{l}\text { Oocyst Recovery } \\
\text { Method }^{+}\end{array}$ & $\begin{array}{l}\text { Detection Methods } \\
\text { (Molecular Target) }\end{array}$ & & \\
\hline Brazil & Drinking water & 8 & $\begin{array}{l}\text { Given ad libitum } \\
\text { to the piglets }\end{array}$ & $\begin{array}{l}\text { Treated (process } \\
\text { not specified) }\end{array}$ & No data & Yes & Directly & $\begin{array}{l}\text { Piglet bioassay: IFAT } \\
\text { Piglet bioassay: tissue } \\
\text { PCR (529 RE) } \\
\text { Piglet bioassay: tissue } \\
\text { mouse bioassay and } \\
\text { PCR (529 RE) }\end{array}$ & $\begin{array}{l}8(100) \\
5(62.5) \\
5(62.5)^{\mathrm{b}}\end{array}$ & [51] \\
\hline Brazil & Farm water & No data (0.003) & No data & No data & Yes & No & $\begin{array}{l}\text { Flotation and } \\
\text { centrifugation }\end{array}$ & $\begin{array}{l}\text { PCR (529 RE) } \\
\text { Mouse bioassay }\end{array}$ & No data & [59] \\
\hline Canada & $\begin{array}{l}\text { Untreated water that } \\
\text { supplied municipal } \\
\text { drinking water } \\
\text { treatment plants }\end{array}$ & 11 & Mean of 1051 & Untreated & No data & Yes & $\begin{array}{l}\text { Filtration, wash, } \\
\text { centrifugation, } \\
\text { flotation, wash, and } \\
\text { centrifugation }\end{array}$ & $\begin{array}{l}\text { Mouse bioassay: } \\
\text { microscopy from tissue } \\
\text { and MAT }\end{array}$ & 0 & [91] \\
\hline Colombia & Water & 40 & 0.2 or 4 & $\begin{array}{l}\text { Boiled and others } \\
\text { not specified }\end{array}$ & No data & Yes & $\begin{array}{l}\text { Sedimentation by } \\
\text { centrifugation with } \\
\text { formalin-ether }\end{array}$ & nPCR (B1) & $4(10.0)^{b, c}$ & [92] \\
\hline Colombia & $\begin{array}{l}\text { Surface water before } \\
\text { and during } \\
\text { treatment, in the } \\
\text { treatment plant } \\
\text { network and from } \\
\text { homes }\end{array}$ & 46 & 10 & $\begin{array}{l}\text { Untreated and } \\
\text { treated: } \\
\text { coagulation, } \\
\text { flocculation, } \\
\text { sedimentation, } \\
\text { filtration, and } \\
\text { chlorination }\end{array}$ & No data & No & $\begin{array}{l}\text { Sedimentation by } \\
\text { centrifugation with } \\
\text { formalin-ether }\end{array}$ & nPCR (B1) & $27(58.6)^{c}$ & [93] \\
\hline Czech Republic & $\begin{array}{l}\text { Irrigation and } \\
\text { vegetables washing } \\
\text { water }\end{array}$ & 18 & 10 & No data & Not data & No & $\begin{array}{l}\text { Filtration, wash, and } \\
\text { centrifugation }\end{array}$ & qPCR (B1 and 529 RE) & 0 & [94] \\
\hline Egypt & Irrigation water & 54 & No data & No data & No data & No & $\begin{array}{l}\text { Filtration and } \\
\text { centrifugation }\end{array}$ & $\begin{array}{l}\text { Mouse bioassay- } \\
\text { smears and MAT }\end{array}$ & $9(16.7)$ & [95] \\
\hline France & Wastewa-ter & 35 & 20 & $\begin{array}{l}\text { Treated and } \\
\text { untreated (process } \\
\text { not specified) }\end{array}$ & No data & No & $\begin{array}{l}\text { Filtration, wash, } \\
\text { centrifugation, } \\
\text { immunomagnetic } \\
\text { separation of } \\
\text { Cryptosporidium spp. } \\
\text { and G. duodenalis, } \\
\text { centrifugation, and } \\
\text { flotation }\end{array}$ & PCR (529 RE) & 0 & [96] \\
\hline
\end{tabular}


Table 2. Cont.

\begin{tabular}{|c|c|c|c|c|c|c|c|c|c|c|}
\hline \multicolumn{7}{|c|}{ Sampling Strategy } & \multicolumn{2}{|c|}{ Methods Used } & \multirow{2}{*}{$\begin{array}{c}\text { Results } \\
\begin{array}{c}\text { Positive Samples } \\
(\%)\end{array}\end{array}$} & \multirow[t]{2}{*}{ Reference } \\
\hline $\begin{array}{l}\text { Sampling } \\
\text { Location } \\
\text { (Country) }\end{array}$ & Sample Details & $\begin{array}{l}\text { No. of Samples } \\
\text { Collected }\end{array}$ & $\begin{array}{l}\text { Sample Volume } \\
\text { Collected } \\
\text { (Sample Volume } \\
\text { Analyzed) } \\
\text { (Liters-L) }\end{array}$ & Water Treatment & $\begin{array}{l}\text { Presence of } \\
\text { Cats }\end{array}$ & $\begin{array}{l}\text { Link with Human } \\
\text { Toxoplasmosis }{ }^{a}\end{array}$ & $\begin{array}{l}\text { Oocyst Recovery } \\
\text { Method }^{+}\end{array}$ & $\begin{array}{l}\text { Detection Methods } \\
\text { (Molecular Target) }\end{array}$ & & \\
\hline France & $\begin{array}{l}\text { Untreated } \\
\text { surface, ground, and } \\
\text { public drinking } \\
\text { water }\end{array}$ & 139 & $100(7-100)$ & No data & No data & No & $\begin{array}{l}\text { Filtration, wash, } \\
\text { centrifugation, } \\
\text { immunomagnetic } \\
\text { separation of } \\
\text { Cryptosporidium spp. } \\
\text { and G. duodenalis, } \\
\text { flotation, } \\
\text { centrifugation, wash, } \\
\text { and centrifugation }\end{array}$ & $\begin{array}{l}\text { qPCR (B1) } \\
\text { Mouse bioassay- } \\
\text { agglutination test and } \\
\text { smear }\end{array}$ & $\begin{array}{l}10(8.0)^{d} \\
0\end{array}$ & [97] \\
\hline France & $\begin{array}{l}\text { Untreated } \\
\text { surface, ground, and } \\
\text { public drinking } \\
\text { water }\end{array}$ & 482 & 5-100 & No data & No data & No & $\begin{array}{l}\text { Filtration, wash, } \\
\text { centrifugation, } \\
\text { immunomannetic } \\
\text { separation of } \\
\text { Cryptosporidium spp. } \\
\text { and G. duodenalis, } \\
\text { centrifugation, } \\
\text { flotation, and } \\
\text { centrifugation }\end{array}$ & PCR (B1 and 529 RE) & $37(7.7)^{\mathrm{e}}$ & [98] \\
\hline Germany & Wastewa-ter & 25 & 1 & $\begin{array}{l}\text { Untreated and } \\
\text { treated: } \\
\text { mechanical and } \\
\text { biological } \\
\text { treatments }\end{array}$ & No data & No & $\begin{array}{l}\text { Filtration (sieve and } \\
\text { cellulose filters), wash, } \\
\text { and centrifugation }\end{array}$ & PCR (B1) & 0 & [99] \\
\hline Germany & $\begin{array}{l}\text { Variable: drinking } \\
\text { water and others not } \\
\text { specified }\end{array}$ & 95 & $5-2500$ & $\begin{array}{l}\text { Treated and } \\
\text { untreated (process } \\
\text { not specified) }\end{array}$ & No data & No & $\begin{array}{l}\text { Flocculation for } \\
\text { WWTPs, filtration for } \\
\text { drinking, groundwater } \\
\text { and surface water, then } \\
\text { centrifugation and } \\
\text { flotation for samples }\end{array}$ & LAMP (B1) & $8(8.4)$ & [100] \\
\hline $\begin{array}{l}\text { Greece } \\
\text { Bulgaria } \\
\text { Japan }\end{array}$ & $\begin{array}{l}\text { River, reservoir, well, } \\
\text { spring, tap, sewage, } \\
\text { and recreational } \\
\text { water }\end{array}$ & $\begin{array}{l}20 \\
34 \\
6\end{array}$ & 10 & No data & No data & No & $\begin{array}{l}\text { Flocculation, } \\
\text { centrifugation, } \\
\text { discontinuous } \\
\text { sucrose gradients, } \\
\text { wash, and } \\
\text { centrifugation }\end{array}$ & nPCR (18S rRNA) & $\begin{array}{l}1(5)^{\mathrm{b}} \\
3(8.8)^{\mathrm{b}} \\
0\end{array}$ & [50] \\
\hline
\end{tabular}


Table 2. Cont.

\begin{tabular}{|c|c|c|c|c|c|c|c|c|c|c|}
\hline \multicolumn{7}{|c|}{ Sampling Strategy } & \multicolumn{2}{|c|}{ Methods Used } & \multirow{2}{*}{$\begin{array}{c}\text { Results } \\
\begin{array}{c}\text { Positive Samples } \\
(\%)\end{array}\end{array}$} & \multirow[t]{2}{*}{ Reference } \\
\hline $\begin{array}{l}\text { Sampling } \\
\text { Location } \\
\text { (Country) }\end{array}$ & Sample Details & $\begin{array}{l}\text { No. of Samples } \\
\text { Collected }\end{array}$ & $\begin{array}{l}\text { Sample Volume } \\
\text { Collected } \\
\text { (Sample Volume } \\
\text { Analyzed) } \\
\text { (Liters-L) }\end{array}$ & Water Treatment & $\begin{array}{l}\text { Presence of } \\
\text { Cats }\end{array}$ & $\begin{array}{l}\text { Link with Human } \\
\text { Toxoplasmosis }^{\text {a }}\end{array}$ & $\begin{array}{l}\text { Oocyst Recovery } \\
\text { Method }^{\dagger}\end{array}$ & $\begin{array}{l}\text { Detection Methods } \\
\text { (Molecular Target) }\end{array}$ & & \\
\hline Iran & Natural water & 34 & 5 & No data & No data & No & $\begin{array}{l}\text { Filtration, wash, } \\
\text { centrifugation, and } \\
\text { flotation }\end{array}$ & LAMP (B1) & $2(5.8)$ & [101] \\
\hline Italy & Wastewa-ter & 119 & $10-20$ & $\begin{array}{l}\text { Sand, membrane- } \\
\text { bioreactor, } \\
\text { plug-flow reactor, } \\
\text { and membrane } \\
\text { ultrafiltration }\end{array}$ & No data & No & $\begin{array}{l}\text { Filtration, wash, } \\
\text { centrifugation, and } \\
\text { flotation }\end{array}$ & qPCR (B1-multiplex) & 0 & [102] \\
\hline Mexico & $\begin{array}{l}\text { Public drinking } \\
\text { water }\end{array}$ & 74 & 5 & Chlorination & No data & No & $\begin{array}{l}\text { Filtration, wash, } \\
\text { centrifugation, } \\
\text { flotation, } \\
\text { centrifugation, wash, } \\
\text { and centrifugation }\end{array}$ & nPCR (SAG1) & $4(5.4)$ & [103] \\
\hline Pakistan & $\begin{array}{l}\text { Drinking, } \\
\text { recreational, and } \\
\text { irrigation water }\end{array}$ & 500 & No data & No data & No data & No & $\begin{array}{l}\text { Flocculation or } \\
\text { filtration }\end{array}$ & PCR (B1 and 529 RE) & $41(8.2)^{b}$ & [78] \\
\hline Poland & Drinking water & 114 & 5 & No data & Yes & Yes & $\begin{array}{l}\text { Filtration, wash, } \\
\text { centrifugation, } \\
\text { flotation with } \\
\text { centrifugation, wash, } \\
\text { and centrifugation }\end{array}$ & PCR (no data) & $31(27.2)$ & [104] \\
\hline Poland & $\begin{array}{l}\text { Drinking and } \\
\text { natural water }\end{array}$ & 201 & 5 & No data & Yes & Yes & $\begin{array}{l}\text { Filtration, wash, } \\
\text { centrifugation, } \\
\text { flotation with } \\
\text { centrifugation, wash, } \\
\text { and centrifugation }\end{array}$ & $\begin{array}{l}\text { PCR (B1) } \\
\text { Mouse bioassay of } 14 \\
\text { PCR positive } \\
\text { samples-tissue PCR or } \\
\text { agglutination test }\end{array}$ & $\begin{array}{l}43(21.4)^{\mathrm{b}, \mathrm{c}} \\
\text { Tissue PCR: } 9 \\
\text { (64.3), } \\
\text { agglutination test: } \\
3(21.4)^{\mathrm{b}}\end{array}$ & [105] \\
\hline Poland & $\begin{array}{l}\text { Bathing and } \\
\text { drinking water }\end{array}$ & 36 & 50 & No data & No data & No & $\begin{array}{l}\text { Filtration, wash, and } \\
\text { centrifugation }\end{array}$ & nPCR (B1) & $7(19.4)^{c}$ & [106] \\
\hline $\begin{array}{l}\text { Russia } \\
\text { Bulgaria }\end{array}$ & Natural water & $\begin{array}{l}16 \\
36\end{array}$ & No data & No data & No data & No & $\begin{array}{l}\text { Flocculation, wash, } \\
\text { and discontinuous } \\
\text { sucrose gradient }\end{array}$ & $\begin{array}{l}\text { nPCR (18S rRNA) } \\
\text { LAMP (B1) }\end{array}$ & $\begin{array}{l}2(12.5)^{\mathrm{f}} \\
5(13.9)^{\mathrm{f}} \\
9(56.3)^{\mathrm{f}} \\
16(44.4)^{\mathrm{f}}\end{array}$ & [107] \\
\hline
\end{tabular}


Table 2. Cont.

\begin{tabular}{|c|c|c|c|c|c|c|c|c|c|c|}
\hline \multicolumn{7}{|c|}{ Sampling Strategy } & \multicolumn{2}{|c|}{ Methods Used } & Results & \multirow[t]{2}{*}{ Reference } \\
\hline $\begin{array}{l}\text { Sampling } \\
\text { Location } \\
\text { (Country) }\end{array}$ & Sample Details & $\begin{array}{l}\text { No. of Samples } \\
\text { Collected }\end{array}$ & $\begin{array}{l}\text { Sample Volume } \\
\text { Collected } \\
\text { (Sample Volume } \\
\text { Analyzed) } \\
\text { (Liters-L) }\end{array}$ & Water Treatment & $\begin{array}{l}\text { Presence of } \\
\text { Cats }\end{array}$ & $\begin{array}{l}\text { Link with Human } \\
\text { Toxoplasmosis }{ }^{\mathrm{a}}\end{array}$ & $\begin{array}{l}\text { Oocyst Recovery } \\
\text { Method }^{\dagger}\end{array}$ & $\begin{array}{l}\text { Detection Methods } \\
\text { (Molecular Target) }\end{array}$ & $\begin{array}{l}\text { Positive Samples } \\
\text { (\%) }\end{array}$ & \\
\hline Rwanda & $\begin{array}{l}\text { Irrigation and } \\
\text { post-harvest } \\
\text { washing water }\end{array}$ & 30 & 1 & $\begin{array}{l}\text { Untreated those } \\
\text { from rivers, } \\
\text { lagoons, } \\
\text { marshlands, and } \\
\text { lakes }\end{array}$ & No data & No & No data & PCR (529 RE) & 0 & [108] \\
\hline Serbia & $\begin{array}{l}\text { Surface water from } \\
\text { rivers }\end{array}$ & 20 & 10 & No data & No data & No & $\begin{array}{l}\text { Filtration, wash, and } \\
\text { centrifugation }\end{array}$ & PCR (529 RE) & $3(15.0)^{\mathrm{c}}$ & [110] \\
\hline $\begin{array}{l}\text { Spain } \\
\text { presumably }\end{array}$ & Irrigation water & 3 & 1.5 & No data & No data & No & Centrifugation & qPCR (18S rRNA) & $1(33.3)^{b, c}$ & [111] \\
\hline Turkey & Natural water & 60 & 10 & No data & No data & No & $\begin{array}{l}\text { Flocculation, } \\
\text { centrifugation, wash, } \\
\text { and discontinuous } \\
\text { sucrose gradient }\end{array}$ & $\begin{array}{l}\text { nPCR (18S rRNA) } \\
\text { LAMP (B1) }\end{array}$ & $\begin{array}{l}7(11.7)^{c, h} \\
15(25.0)\end{array}$ & [112] \\
\hline $\begin{array}{l}\text { The United } \\
\text { States }\end{array}$ & $\begin{array}{l}\text { Presumably } \\
\text { drinking water for } \\
\text { animals }\end{array}$ & No data & 0.05 & No data & Yes & No & Centrifugation & $\begin{array}{l}\text { Mouse } \\
\text { bioassay-agglutination } \\
\text { test and examination }\end{array}$ & No data & [83] \\
\hline
\end{tabular}

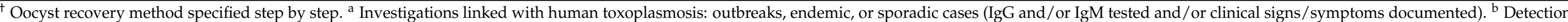

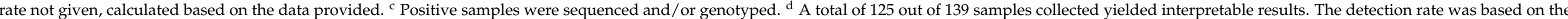

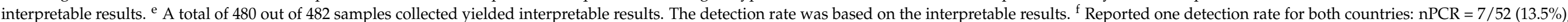

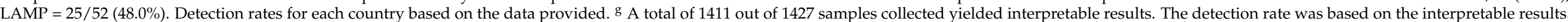

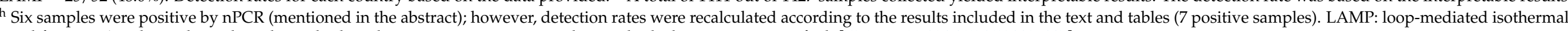
amplification. Articles with results only or also based on microscopy assay or other methods that were not specified: $[78,86,96,99,104,105,107,113-117]$. 
Table 3. Worldwide detection of Toxoplasma gondii oocysts in fresh produce (vegetables and fruit) based on molecular and bioassay methods in articles published up to the end of 2020.

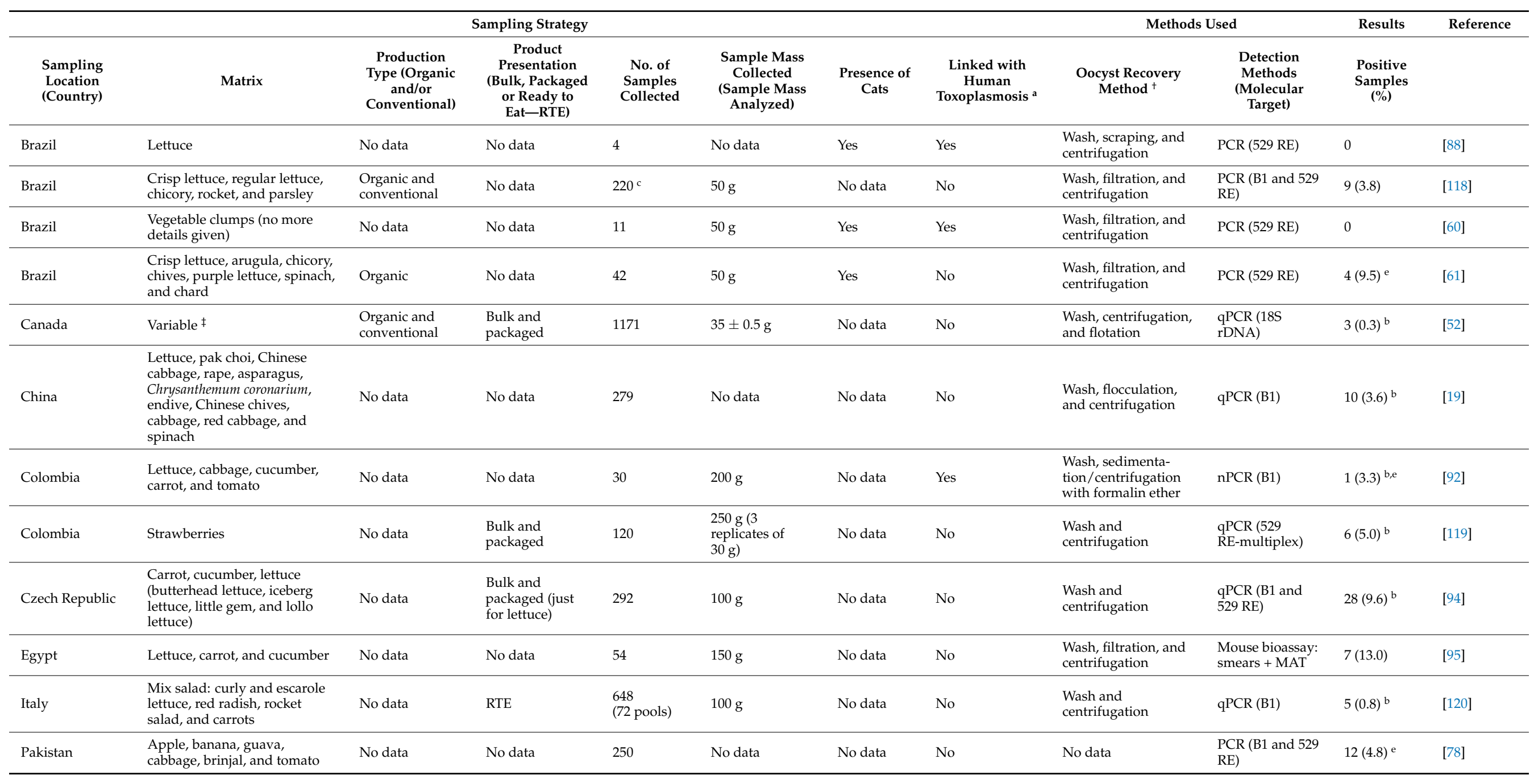


Table 3. Cont.

\begin{tabular}{|c|c|c|c|c|c|c|c|c|c|c|c|}
\hline \multicolumn{8}{|c|}{ Sampling Strategy } & \multicolumn{2}{|c|}{ Methods Used } & \multirow{2}{*}{$\begin{array}{l}\text { Results } \\
\text { Positive } \\
\text { Samples } \\
\text { (\%) }\end{array}$} & \multirow[t]{2}{*}{ Reference } \\
\hline $\begin{array}{l}\text { Sampling } \\
\text { Location } \\
\text { (Country) }\end{array}$ & Matrix & $\begin{array}{l}\text { Production } \\
\text { Type (Organic } \\
\text { and/or } \\
\text { Conventional) }\end{array}$ & $\begin{array}{c}\text { Product } \\
\text { Presentation } \\
\text { (Bulk, Packaged } \\
\text { or Ready to } \\
\text { Eat-RTE) }\end{array}$ & $\begin{array}{l}\text { No. of } \\
\text { Samples } \\
\text { Collected }\end{array}$ & $\begin{array}{l}\text { Sample Mass } \\
\text { Collected } \\
\text { (Sample Mass } \\
\text { Analyzed) }\end{array}$ & $\begin{array}{l}\text { Presence of } \\
\text { Cats }\end{array}$ & $\begin{array}{l}\text { Linked with } \\
\text { Human } \\
\text { Toxoplasmosis a }\end{array}$ & $\begin{array}{l}\text { Oocyst Recovery } \\
\text { Method }^{+}\end{array}$ & $\begin{array}{l}\text { Detection } \\
\text { Methods } \\
\text { (Molecular } \\
\text { Target) }\end{array}$ & & \\
\hline Poland & $\begin{array}{l}\text { Strawberries, radish, carrot, } \\
\text { and lettuce }\end{array}$ & No data & No data & 216 & $\begin{array}{l}1-20 \text { units, } \\
500-1000 \mathrm{~g}\end{array}$ & $\begin{array}{l}\text { Yes (in } \\
\text { farms- } \\
\text { home gar- } \\
\text { dens) }\end{array}$ & No & $\begin{array}{l}\text { Wash, flocculation, } \\
\text { and centrifugation }\end{array}$ & qPCR (B1) & $21(9.7)^{\mathrm{b}}$ & [38] \\
\hline $\begin{array}{l}\text { Spain } \\
\text { Portugal }\end{array}$ & $\begin{array}{l}\text { Lettuce, carrot, parsley, } \\
\text { watercress, coriander, mix } \\
\text { salad, arugula, strawberries, } \\
\text { raspberries, and blueberries }\end{array}$ & $\begin{array}{l}\text { Organic and } \\
\text { conventional }\end{array}$ & $\begin{array}{l}\text { Bulk, packaged, } \\
\text { and RTE }\end{array}$ & $\begin{array}{l}9 \\
26\end{array}$ & $64-3600 \mathrm{~g}$ & No data & No & $\begin{array}{l}\text { Wash, centrifugation, } \\
\text { immunomagnetic } \\
\text { separation of } \\
\text { Cryptosporidium spp. } \\
\text { and G. duodenalis }\end{array}$ & PCR (529 RE) & $\begin{array}{l}2(22.2)^{\mathrm{b}, \mathrm{d}} \\
13(50.0)^{\mathrm{b}, \mathrm{d}}\end{array}$ & [37] \\
\hline Switzerland & $\begin{array}{l}\text { Lettuce (different types, but } \\
\text { not specified) }\end{array}$ & No data & No data & 100 & $\begin{array}{l}900-1800 \mathrm{~g} \\
\text { (pools of } 9 \\
\text { lettuce) }\end{array}$ & No data & No & $\begin{array}{l}\text { Wash, filtration, and } \\
\text { centrifugation }\end{array}$ & PCR (B1) & $6(6.0)^{\mathrm{b}, e}$ & [121] \\
\hline
\end{tabular}

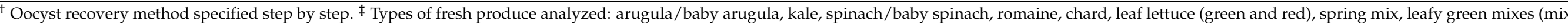

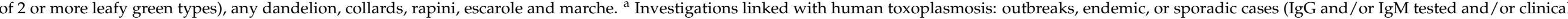

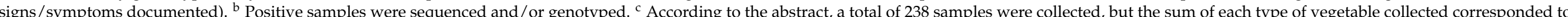

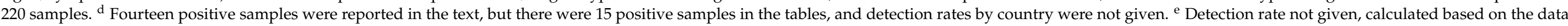
reported. Articles with results only or also based on microscopy assay or other methods that were not specified: [120,122-129].

Table 4. Worldwide detection of Toxoplasma gondii oocysts in bivalve mollusks based on molecular and bioassay methods in articles published up to the end of 2020 .

\begin{tabular}{|c|c|c|c|c|c|c|c|c|}
\hline \multicolumn{5}{|c|}{ Sampling Strategy } & \multicolumn{2}{|c|}{ Methods Used } & Results & Reference \\
\hline $\begin{array}{l}\text { Sampling Location } \\
\text { (Country) }\end{array}$ & $\begin{array}{l}\text { Sample Type (Scientific } \\
\text { Names) }\end{array}$ & Samples Collected & $\begin{array}{l}\text { Sample Units per Pool } \\
\text { or Sample Mass } \\
\text { (Length) }\end{array}$ & $\begin{array}{l}\text { Type of Tissue or } \\
\text { Material Analyzed }\end{array}$ & $\begin{array}{l}\text { Oocyst Recovery } \\
\text { Method }^{+}\end{array}$ & $\begin{array}{c}\text { Detection Methods } \\
\text { (Molecular Target if } \\
\text { Apply) }\end{array}$ & \multicolumn{2}{|l|}{ Positive Samples (\%) } \\
\hline Brazil & $\begin{array}{l}\text { Oysters (Crassostrea } \\
\text { rhizophorae), mussels } \\
\text { (Mytella guyanensis) }\end{array}$ & 80 pools & 5-15 units/pool & Whole oyster or mussel & $\begin{array}{l}\text { Wash, filtration, } \\
\text { centrifugation, wash, } \\
\text { and centrifugation }\end{array}$ & $\begin{array}{l}\text { nPCR (B1) } \\
\text { Mouse bioassay- smear + } \\
\text { IFAT }\end{array}$ & $\begin{array}{l}2(2.5)^{a, b} \\
0\end{array}$ & [130] \\
\hline Brazil & $\begin{array}{l}\text { Oysters (Crassostrea } \\
\text { rhizophorae) }\end{array}$ & 208 pools of each tissue & 3 units/pool (no data) & $\begin{array}{l}\text { Gills and } \\
\text { digestive glands }\end{array}$ & Not performed $*$ & $\begin{array}{l}\text { PCR (529 RE) } \\
\text { nPCR (SAG1) }\end{array}$ & $\begin{array}{l}0 \\
17(8.1)^{\mathrm{b}}\end{array}$ & [131] \\
\hline Brazil & Oysters (Crassostrea spp.) & 120 pools & 10 units/pool (no data) & $\begin{array}{l}\text { Gills, gastrointestinal } \\
\text { tract, and intervalvular } \\
\text { liquid }\end{array}$ & Not performed * & nPCR (B1) & $7(5.8)^{b}$ & [132] \\
\hline Brazil & Oysters (Crassostrea spp.) & 80 pools of each tissue & 5 units/pool (no data) & $\begin{array}{l}\text { Gills and } \\
\text { digestive glands } \\
\text { (visceral mass) }\end{array}$ & Not performed ${ }^{*}$ & nPCR (SAG1) & $2(2.5)^{b}$ & [54] \\
\hline
\end{tabular}


Table 4. Cont.

\begin{tabular}{|c|c|c|c|c|c|c|c|c|}
\hline \multicolumn{5}{|c|}{ Sampling Strategy } & \multicolumn{2}{|c|}{ Methods Used } & Results & \multirow[t]{2}{*}{ Reference } \\
\hline $\begin{array}{l}\text { Sampling Location } \\
\text { (Country) }\end{array}$ & $\begin{array}{c}\text { Sample Type (Scientific } \\
\text { Names) }\end{array}$ & Samples Collected & $\begin{array}{l}\text { Sample Units per Pool } \\
\text { or Sample Mass } \\
\text { (Length) }\end{array}$ & $\begin{array}{l}\text { Type of Tissue or } \\
\text { Material Analyzed }\end{array}$ & $\begin{array}{l}\text { Oocyst Recovery } \\
\text { Method }^{+}\end{array}$ & $\begin{array}{c}\text { Detection Methods } \\
\text { (Molecular Target if } \\
\text { Apply) }\end{array}$ & Positive Samples (\%) & \\
\hline China & Oysters (not specified) & 998 & 1 unit (no data) & $\begin{array}{l}\text { Hemolymph, } \\
\text { digestive glands } \\
\text { and gills }\end{array}$ & Centrifugation & Semi nPCR (B1) & $26(2.6)^{\mathrm{b}}$ & [133] \\
\hline China & Mussels (Mytilus edulis) & 2215 & 1 unit (no data) & $\begin{array}{l}\text { Gills, digestive glands } \\
\text { and hemolymph }\end{array}$ & Not performed * & Semi nPCR (B1) & $55(2.5)^{\mathrm{b}}$ & [134] \\
\hline China & Oysters (Concha ostreae) & 398 & $1 \mathrm{~g} /$ sample (no data) & Digestive tract tissues & Not performed * & PCR (ITS1) & 0 & [135] \\
\hline Italy & $\begin{array}{l}\text { Mussels } \\
\text { (Mytilus galloprovincialis) }\end{array}$ & 409 & $25 \mathrm{mg}(>5 \mathrm{~cm})$ & Digestive gland & Not performed * & qPCR (B1) & $43(10.5)^{b}$ & [137] \\
\hline Italy & $\begin{array}{l}\text { Mussel } \\
\text { (Mytilus galloprovincialis, } \\
\text { Mytilus edulis) }\end{array}$ & 135 pools & $10 \mathrm{~g}$ (no data & Intestinal tissues & $\begin{array}{l}\text { Wash, filtration, } \\
\text { centrifugation, wash, } \\
\text { and centrifugation }\end{array}$ & $\begin{array}{l}\text { End-point PCRs (B1 and } \\
529 \mathrm{RE})\end{array}$ & $10(7.4)^{\mathrm{b}}$ & [138] \\
\hline Italy & $\begin{array}{l}\text { Oysters (Crassostrea gigas), } \\
\text { mussels } \\
\text { (Mytilus galloprovincialis), } \\
\text { clams (Tapes philippinarum, } \\
\text { Tapes decussatus) }\end{array}$ & 62 pools of each tissue & $\begin{array}{l}\text { 11-30 units/pool } \\
\text { (no data) }\end{array}$ & $\begin{array}{l}\text { Digestive glands, gills } \\
\text { and hemolymph }\end{array}$ & $\begin{array}{l}\text { For hemolymph: } \\
\text { flotation, } \\
\text { centrifugation, wash, } \\
\text { and centrifugation. Not } \\
\text { specified for } \\
\text { digestive glands } \\
\text { and gills }\end{array}$ & $\begin{array}{l}\text { nPCR and FLAG- } q P C R \\
\text { (B1) }\end{array}$ & $2(3.2)$ & [139] \\
\hline New Zealand & Mussels (Perna canaliculus) & 104 & 1 unit (no data) & Hemolymph & Centrifugation & nPCR (dhps) & $13(12.5)^{b}$ & [23] \\
\hline Tunisia & $\begin{array}{l}\text { Clams (Ruditapes decussatus), } \\
\text { oysters (Pinctada radiata), } \\
\text { mussels } \\
\text { (Mytilus galloprovincialis, } \\
\text { Perna perna) }\end{array}$ & 87 pools & $\begin{array}{l}\text { 9-18 units/pool } \\
\text { (no data) }\end{array}$ & No data & $\begin{array}{l}\text { Wash, filtration, } \\
\text { centrifugation, wash, } \\
\text { and centrifugation }\end{array}$ & qPCR (B1) & $4(4.6)^{a, b}$ & [140] \\
\hline Turkey & $\begin{array}{l}\text { Mussels } \\
\text { (Mytilus galloprovincialis) }\end{array}$ & 53 pools & 15 units/pool $(5-8 \mathrm{~cm})$ & $\begin{array}{l}\text { Gills and digestive } \\
\text { system }\end{array}$ & $\begin{array}{l}\text { Filtration and } \\
\text { centrifugation }\end{array}$ & $\mathrm{qPCR}(\mathrm{B} 1)+\mathrm{HRM}$ & $5(9.4)^{b}$ & [141] \\
\hline $\begin{array}{l}\text { Turkey } \\
\text { Italy }\end{array}$ & $\begin{array}{l}\text { Mussels } \\
\text { (Mytilus galloprovincialis) }\end{array}$ & $\begin{array}{l}53 \text { pools } \\
60 \text { pools }\end{array}$ & $\begin{array}{l}15 \text { units/pool (no data) } \\
500 \mathrm{~g} \text { (no data) }\end{array}$ & $\begin{array}{l}\text { Gills and digestive } \\
\text { system } \\
\text { Hemolymph, gills and } \\
\text { digestive glands }\end{array}$ & $\begin{array}{l}\text { Flotation or filtration } \\
\text { and centrifugation }\end{array}$ & qPCR + HRM (B1) & $\begin{array}{l}7(13.2) \\
0\end{array}$ & [102] \\
\hline The United States & $\begin{array}{l}\text { Oysters (Crassostrea } \\
\text { virginica) }\end{array}$ & 1440 & $\begin{array}{l}50-100 \mathrm{mg} \\
\text { wet weight of total } \\
\text { tissue (no data) }\end{array}$ & $\begin{array}{l}\text { Mantle, gills and } \\
\text { rectum }\end{array}$ & Not performed * & qPCR (ITS1) & $446^{\mathrm{a}}(31.0)$ & [55] \\
\hline The United States ${ }^{\ddagger}$ & $\begin{array}{l}\text { Mussels ( } M \text {. } \\
\text { californianus), gaper clams } \\
\text { (Tresus nuttallii), pismo } \\
\text { clams (Tivela stultorum) }\end{array}$ & 1109 & $\begin{array}{l}50 \mathrm{mg} \text { of digestive } \\
\text { tissue or } 50-100 \mu \mathrm{L} \text { of } \\
\text { pelleted hemolymph } \\
\text { (no data) }\end{array}$ & $\begin{array}{l}\text { Hemocytes and } \\
\text { digestive gland }\end{array}$ & Not performed * & qPCR (18S rRNA) & $1(0.1)^{a, b}$ & {$[21]$} \\
\hline
\end{tabular}


Table 4. Cont.

\begin{tabular}{|c|c|c|c|c|c|c|c|c|}
\hline \multicolumn{5}{|c|}{ Sampling Strategy } & \multicolumn{2}{|c|}{ Methods Used } & \multirow{2}{*}{$\begin{array}{c}\text { Results } \\
\text { Positive Samples (\%) }\end{array}$} & \multirow[t]{2}{*}{ Reference } \\
\hline $\begin{array}{l}\text { Sampling Location } \\
\text { (Country) }\end{array}$ & $\begin{array}{c}\text { Sample Type (Scientific } \\
\text { Names) }\end{array}$ & Samples Collected & $\begin{array}{l}\text { Sample Units per Pool } \\
\text { or Sample Mass } \\
\text { (Length) }\end{array}$ & $\begin{array}{l}\text { Type of Tissue or } \\
\text { Material Analyzed }\end{array}$ & $\begin{array}{l}\text { Oocyst Recovery } \\
\text { Method }^{+}\end{array}$ & $\begin{array}{c}\text { Detection Methods } \\
\text { (Molecular Target if } \\
\text { Apply) }\end{array}$ & & \\
\hline The United States ${ }^{\ddagger}$ & $\begin{array}{l}\text { Mussels (Mytilus } \\
\text { californianus) }\end{array}$ & 959 & 1 unit (no data) & Hemolymph & Centrifugation & nPCR (ITS1 and B1) & $13(1.4)^{\mathrm{b}}$ & [22] \\
\hline The United States & Mussels (Mytilus spp.) & 41 & 1 unit (no data) & $\begin{array}{l}\text { Hemolymph, gills and } \\
\text { digestive glands }\end{array}$ & $\begin{array}{l}\text { Filtration and } \\
\text { centrifugation }\end{array}$ & $\begin{array}{l}\text { qPCR and end- point PCR } \\
\text { (529 RE) }\end{array}$ & $19(46.3)^{a, b}$ & [53] \\
\hline The United States & $\begin{array}{l}\text { Clams (Mya arenaria), } \\
\text { mussels (Geukensia demissa, } \\
\text { Mytilus edulis), oysters } \\
\text { (Crassostrea virginica) }\end{array}$ & 159 & 1 unit (no data) & $\begin{array}{l}\text { Digestive gland, } \\
\text { mantle, gills, foot, and } \\
\text { siphon }\end{array}$ & Not performed * & PCR (GRA6) & 0 & [142] \\
\hline The United States & $\begin{array}{l}\text { Mussel (Mytilus } \\
\text { californianus) }\end{array}$ & $\begin{array}{l}\text { Analyzed pools, but the } \\
\text { exact number was not } \\
\text { Specified (total of } \\
\text { units = 959) }\end{array}$ & 30 units $/ \operatorname{pool}(\geq 3 \mathrm{~cm})$ & Hemolymph & Not performed * & PCR (ITS1, $529 \mathrm{bp}$ and B1) & $13(1.5)^{b, c}$ & [117] \\
\hline
\end{tabular}

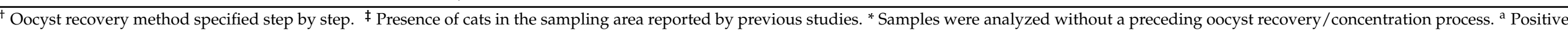

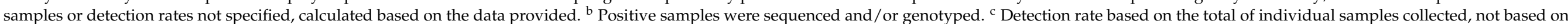
analyzed pools. HRM: high-resolution melt curve. FLAG: fluorescent amplicon generation. IFAT: indirect immunofluorescence test. None of the articles were linked to human toxoplasmosis. 
Most studies were focused on a few countries, so data cannot be extrapolated to other areas. The fact that most of the studies included in this systematic review were performed in North and South America could be linked to the frequency of oocyst-associated toxoplasmosis outbreaks, which were documented as early as 1966 in these regions [143]. Brazil is the country most represented in the studies, which is likely because it is a hotspot for outbreaks and the presence of a wide variety of strains that appear more virulent [7].

It is noticeable that very few studies addressed $T$. gondii infection using a multisectoral and transdisciplinary approach, according to the One Health concept. Indeed, only 13 of the selected articles studied the association between oocyst detection in environmental matrices with human T. gondii infection and toxoplasmosis (outbreaks, endemic, or sporadic cases), most of them from North and South America. Five of these studies focused on soil $[56,60,70,77,80]$, with three of them reporting positive samples; 10 were in water [51,60,70,87-89,91,92,104,105], with eight reporting positive samples; and three were on fresh produce $[60,88,92]$, with one reporting positive samples and the other reporting negative samples, but suggesting that the occurrence of toxoplasmosis was connected with vegetable consumption in a restaurant [60] (Tables 1-4).

\subsection{Sampling Strategies}

The studies selected were not comparable due to the large differences between them. When analyzing pooled detection rates by matrix type, a high degree of heterogeneity was observed $\left(\mathrm{I}^{2}=98.9 \%, p<0.001\right)$ due to the different sampling and methodological approaches adopted among the 64 studies included here (Table 5). Fresh produce stood out as the least heterogeneous matrix $\left(\mathrm{I}^{2}=78.2 \%, p<0.001\right)$. Nevertheless, this might be a consequence of the small number of studies selected $(n=8)$ because most of the available surveys analyzed pooled samples and were excluded. A larger number of studies $(n=28)$ were considered for water. However, high heterogenicity was obtained $\left(\mathrm{I}^{2}=85.4 \%, p<0.001\right)$ even though sampling strategies were adopted from standardized protocols for other waterborne parasites such as Cryptosporidium spp. and G. duodenalis [144]. As expected, similar results were found when analyzing heterogeneity by Cochran's chi-squared $(\mathrm{Q}=6679.21$ (d.f. $=74), P<0.001)$. In addition, the first approach to estimate the sampling bias showed a significant influence (Egger's test $=4.41, p<0.001$ ), which provides additional statistical evidence of heterogeneous sampling strategies and methodologies [41,145] (Tables 1-4; Supplementary Figures S1-S4). Such bias was also evident in the funnel plots constructed for each of the matrices (Supplementary Figure S5). Nevertheless, we did not exclude any of the studies aiming to show a detailed overview of the investigations carried out up to date. Thus, harmonized procedures should be implemented in future studies.

Table 5. Subgroup analysis for comparison of the occurrence of Toxoplasma gondii oocysts detected by molecular methods in each matrix.

\begin{tabular}{ccccccccc}
\hline \multirow{2}{*}{ Matrix } & \multirow{2}{*}{$\begin{array}{c}\text { No. of Studies } \\
\text { Included }\end{array}$} & \multirow{2}{*}{$\begin{array}{c}\text { Pooled Detection } \\
\text { Rates (95\% CI) }\end{array}$} & \multicolumn{3}{c}{ Heterogeneity Test } & \multicolumn{3}{c}{ Egger's Test } \\
\cline { 5 - 9 } & & $\mathbf{I}^{\mathbf{2}} \mathbf{( \% )}$ & $\boldsymbol{Q}\left(\boldsymbol{X}^{\mathbf{2}}\right)$ & $\mathbf{Q} / \mathbf{d f}$ & $\mathbf{Q - p}(\boldsymbol{P})$ & $\boldsymbol{t}$ & $\boldsymbol{p}$ \\
\hline Soil & 25 & $17.3(11.0-23.7)$ & 99.3 & 3388.03 & 24 & $<0.001$ & 1.08 & 0.292 \\
Water & $28^{\mathrm{a}}$ & $9.2(6.3-12.0)$ & 85.4 & 205.09 & 23 & $<0.001$ & 2.33 & 0.030 \\
Fresh produce & $8^{\mathrm{b}}$ & $5.2(1.7-8.8)$ & 78.2 & 36.76 & 8 & $<0.001$ & 9.09 & $<0.001$ \\
Bivalve mollusks & $1^{\mathrm{c}}$ & $6.8(4.4-9.2)$ & 98.8 & 757.99 & 9 & $<0.001$ & 2.82 & 0.030 \\
Total & $71^{*}$ & $12.0(10.0-14.0)$ & 98.9 & 6679.21 & 74 & $<0.001$ & 4.41 & $<0.001$ \\
\hline
\end{tabular}

$\mathrm{I}^{2}$, inverse variance index; $\mathrm{Q}$, Cochran's $\mathrm{X}^{2} ; \mathrm{Q}-\mathrm{P} p$-value of Q-tests. ${ }^{*}$ Few articles analyzed samples from more than one country. ${ }^{a}$ Excluded: [59,89] (the number of positive samples was not specified). ${ }^{b}$ Excluded: [60,78,92,119-121] (analyzed pooled samples). ${ }^{\mathrm{c}}$ Excluded: [54,102,117,130-132,136,138-141] (analyzed pooled samples).

\subsubsection{Soil}

Soil samples were grouped into different categories according to their origin, which was mainly based on their proximity to urban areas and the presence of domestic and wild felids: public parks and playgrounds, schools, gardens, backyards, and houses (in- 
cluding vegetable gardens/orchards), livestock farms, crop fields and grasslands, and forests (Table 1, Supplementary Table S2). In general, the detection rates in soil near urban areas were between 1.1\% (10/924) in playgrounds [77] and 94.1\% (16/17) in vegetable gardens [72]. On livestock farms, detection rates ranged from 1.0\% (7/700) [48] to 100\% $(5 / 5)$ [49], in crop fields and grasslands from $20.0 \%(2 / 10)$ [61] to $32.4 \%$ (274/845) [65], and in forests from 32.1\% (26/81) [69] to 85.7\% (6/7) [72] (Supplementary Table S2).

The higher detection rates reported in livestock farms, vegetable gardens, and forests may be explained by the presence of felines, since 20 out of 23 articles that documented the presence of cats near the sampling area also reported positive samples. There is evidence that T. gondii oocyst contamination is more common at known cat defecation sites than at other sites [68], and in farms with higher cat densities [63]. In a study in eastern France, soil contamination with oocysts decreased as the distance from core areas of cat home ranges increased [69]. In studies reporting the presence of cats, the detection rates ranged from $1.1 \%$ (10/924) [77] to 78.1\% (150/192) [72], whereas they ranged from 1.0\% (7/700) [48] to 100\% $(5 / 5)$ [49] in studies where no information was provided. For further studies that aim to determine the risk that the presence of cats poses to T. gondii environmental contamination, quantitative data on cat colonies would help to better interpret the results obtained.

The prevalence of oocyst-shedding cats may vary with seasonal reproductive patterns, and the likelihood of exposure to T. gondii may be influenced by climatic conditions [62]. There is evidence that season and extreme weather events are variables that influence T. gondii contamination. T. gondii oocysts remain viable for a long period of time in moist soil conditions and mild temperatures. For example, significant levels of rainfall may lead to humidity, precipitation, and excess runoff, and thus, exposure to T. gondii oocyst is increased [12,21]. In contrast, drier conditions and hot temperatures reduce the persistence (and viability) of T. gondii oocysts in the soil [82,146]. A handful of studies have investigated the effects of climate conditions and season on soil contamination with T. gondii oocysts. Soil, temperature, and humidity were found to be associated with oocyst contamination in Harbin, China [65]. In another study from China, soil contamination was more common in a sub-tropical climate [62]. In three studies, oocyst positive soil samples were found more frequently in autumn $[48,62,82]$. In contrast, a gradual decrease in soil detection rates from spring to winter was reported in Wuhan, China [63], and levels of soil contamination were higher in the summer season than in the spring in Mazandaran Province, Iran [72]. Local variations in climate may explain the seasonal differences observed, and this highlights the importance of recording climatic conditions when undertaking environmental sampling.

Other sampling variables to be considered are the number of samples collected that ranged from 5 [56] to 9420 [65], the mass of soil sampled that varied from $1 \mathrm{~g}$ [59] to $1000 \mathrm{~g} \mathrm{[58]}$ and the sampling depth that ranged between 2 and $10 \mathrm{~cm}$ (Table 1). However, this information was not provided in some articles, and thus, comparison between articles was not possible.

Currently, there is a lack of knowledge on the nature or extent of any effect of soil type on T. gondii oocyst survival. The biological, chemical, and physical parameters of soil may vary with soil type and sampling season and therefore affect oocysts' viability, recovery, and detection. An experimental study conducted with T. gondii oocysts and different types of artificial and natural soil matrices demonstrated that the efficiency of oocyst recovery is affected by the soil characteristics, with significantly higher efficiency from samples that had the lowest sand content [147], which was probably due to the structural damage caused by mixing before and during the flotation procedure, as documented previously for Cryptosporidium spp. [148]. Therefore, all these parameters should be documented to facilitate the development of risk assessment and management strategies aimed at detecting T. gondii oocysts, estimating the environmental contamination burden, and reducing public health risks [62]. 


\subsubsection{Water}

Regarding investigations on the occurrence of $T$. gondii oocysts in water, specific sampling variables were considered: the water origin (groundwater: wells; surface: rivers, beaches, lakes, pools; wastewater; piped water: from homes or public drinking water), uses (recreational: swimming and/or playing sports; irrigation/washing; potable water) and water treatment (boiling, chlorination, filtration) (Table 2, Supplementary Table S3).

Toxoplasma gondii detection rates ranged from 5.4\% (4/74) [103] to 37.5\% (30/80) [104] in groundwater water, $5.0 \%(5 / 100)$ [98] to $76.9 \%(10 / 13)$ [93] in surface water, $10.0 \%$ $(1 / 10)$ [50] to $42.9 \%$ (3/7) [107] in wastewater, and $2.3 \%(1 / 44)$ [97] to $17.9 \%(5 / 28)$ in piped water. Lower $T$. gondii detection rates in drinking water and groundwater compared to surface water have been reported previously [78]. This could be due to the water treatment received or natural filtration through soil, stones, and organic matter, respectively. However, this last hypothesis will depend on the characteristics of the ground, since material of smaller diameter could retain more oocysts, as experimentally proven for Cryptosporidium spp. oocysts [149]. It is also possible that inhibitors that might affect molecular tests are more likely present in groundwater or wastewater, leading to an underestimation of the contamination with oocysts. Surface water may be directly in contact with definitive host feces or accumulated rainfall runoff from surfaces, leading to higher oocyst contamination.

The public health importance of different contaminated water sources is determined by their uses. In relation to this, one article reported 9.0\% (9/100) recreational water samples to be oocyst positive [78], while the detection rates were between $16.7 \%(9 / 54)$ [95] and $50.0 \%(1 / 2)$ [88] in irrigation/washing water, and 2.3\% (1/44) [97] and $100 \%(8 / 8)$ [51] in potable water. The origin of these samples was not specified in all cases; the recreational water corresponded to lakes and pools, the irrigation/washing water was from a river, and in one study, the potable water corresponded to water kept in tanks/towers from houses, in fountains, and from the water and sewage company. One study with $100 \%$ of positive potable water samples was linked to a human toxoplasmosis outbreak in Santa Maria, Brazil, which was one of the largest studies worldwide with around 902 confirmed cases [51] and one of the few that used piglet bioassay for parasite detection; thus, oocysts infectivity was confirmed.

Previous studies have stated that untreated surface irrigation water is a relevant source of waterborne pathogens including T. gondii [111] and that human T. gondii infection seropositivity is significantly more frequent among those consuming unboiled water [104]. Herein, three out of eight articles that analyzed treated water clearly specified the treatment received, all from North and South America, with detection rates of 5.4\% (4/74) in chlorinated water [103], 6.0\% (2/30) in boiled water [92], and 60.0\% $(12 / 20)$ in water from the distribution system of a treatment plant after a coagulation, flocculation, sedimentation, filtration, and chlorination process [93]. However, oocyst viability was not assessed in these studies, and it is documented that sporulated oocysts lose their infectivity at $60{ }^{\circ} \mathrm{C}$ for $1 \mathrm{~min}$ [150], while treatments such as chlorination, ultraviolet (UV), and ozone are not effective [151]. One study that analyzed treated water reported $100 \%(8 / 8)$ of positive samples by piglet bioassay, which were linked to a human toxoplasmosis outbreak, but water treatment was not specified [51]. This finding could indicate that not all treatments used are effective or that treated water may become contaminated, which is more likely in countries with inadequate water supply systems. Thus, in addition to avoiding the contamination of stored water (tanks, cisterns, and others), the effectiveness of treatments and the post-treatment handling are both crucial factors to be considered in the prevention and control of water-related toxoplasmosis.

The number of samples collected was extremely variable: from three irrigation, municipal, and/or cistern water samples $[60,88,111]$ to 1427 public water supply samples [109]. In addition, the sample volume ranged from $0.01 \mathrm{~L}$ [61] to up to $2500 \mathrm{~L}$ [100]. The analysis of large volumes is necessary because of the low oocyst load expected. However, water turbidity due to organic matter can also have an impact, since this can lead to mem- 
brane saturation [70] and increase the possibility of the presence of inhibitors affecting the molecular tests.

Altogether, nine articles recorded the presence of cats in the sampling area, and six of them reported positive samples $[61,70,88,89,104,105]$ (Table 2). However, no clear association was established. One article suspected that reservoir contamination was due to a cat from the area that gave birth to kittens that lived on the top of the reservoir, but they could not be caught, and so it was not possible to confirm this hypothesis [89]. Since most of the studies did not specify whether cats were present, it was not possible to determine if reported detection rates were influenced by this variable. Moreover, the presence of cats alone is insufficient to explain the results, since infected cats can shed oocysts that could contaminate areas located far away from the sampling sites through water currents.

Detection rates by sampling season were not documented in most studies. One study in Scotland (UK) reported a higher number of positive samples in autumn compared to summer [109], and other studies in Mexico and Brazil found positive samples only during the rainy season $[90,103]$. In addition, a study in French Guiana, linked to a human toxoplasmosis outbreak, stated that climate changes, mainly flooding and warming, were the prelude to the event [70]. Therefore, it seems that there is a positive association between wet seasons and the presence of oocysts in water samples; however, further studies are required to confirm this. A higher probability of detecting Cryptosporidium spp. and G. duodenalis in fresh surface water during and after extreme weather events has been also documented, with mean odds ratios of $2.61(95 \% \mathrm{CI}=1.63-4.21)$ and 2.87 $(95 \% \mathrm{CI}=1.76-4.67)$, respectively [152]. Accordingly, apart from classical climatologic parameters such as temperature and humidity, extreme weather events might strongly influence oocyst presence, and this should be taken into account in risk assessments.

\subsubsection{Fresh Produce}

Regarding fresh produce, sampling strategies varied in terms of matrix composition, number and mass of samples, season, origin (growing location: gardens/orchards, open fields, green houses; market: local markets and fairs, supermarkets, or restaurants), production type (organic versus conventional), and product presentation (bulk, prepacked, and RTE) (Table 3, Supplementary Table S4).

Fresh produce is a heterogeneous matrix that was divided into four distinct categories in this study: leafy greens including mixed salads $(n=13)$, non-leafy vegetables including root crops and others (brinjal, asparagus, beet, radish, carrot, chives, chili, tomato; $n=9$ ), herbs (basil, dill, chicory, coriander, thyme, parsley; $n=3$ ), and fruit (apple, banana, guava, blueberry, raspberry, and strawberry; $n=3$ ). Leafy greens included different types of lettuce, chicory, rocket (syn. Arugula), watercress, chard, spinach/baby spinach, and Brassica vegetables (cabbage, red cabbage, rape, pak choi). Lettuce was investigated in 12 studies, but a harmonized nomenclature was not found, since the type of lettuce was not specified in seven studies, whilst in others, the authors mentioned romaine, red and green leaf lettuce, regular lettuce, curly lettuce, butterhead lettuce, iceberg (syn. Crisp) lettuce, little gem, lollo lettuce, escarole, or simply "varieties of lettuce". In addition to this, 13 studies analyzed one type of sample, whereas three studies analyzed a mix of vegetables. The composition of fresh produce might influence the possibility of being contaminated with oocysts, since the production process and growing period differ notably between baby leaves, grown and cut leafy greens, roots, and fruit.

According to the product presentation, three studies analyzed a mixture of leafy greens, and two of them were specifically RTE products, with detection rates of $0.8 \%(5 / 648)$ [120] and $33.3 \%(2 / 6)$ [37]. Apart from these mixed salads, samples of arugula and watercress were also RTE, with $66.7 \%(2 / 3)$ of positive samples only in the last case [37]. The differences in detection rates may be at least partially explained by the number of samples collected and tested. It is clear that current RTE production processes do not guarantee a product free from parasites of fecal origin, as not only T. gondii but also Cryptosporidium spp., G. duodenalis, Cyclospora cayetanensis, Blastocystis hominis, and Dientamoeba fragilis have been 
detected in RTE products, [120]. By contrast, a recent study performed in Italy did not detect T. gondii in 324 locally produced RTE mixed salads [153]. However, Echinococcus granulosus was detected in one sample, providing evidence for the risk of being contaminated with parasites of fecal origin [153].

The number of samples analyzed varied from one study to another, from one arugula, spinach, or chard sample [37,61] to 387 baby spinach samples [52], and three pools of cabbages [92] to 100 pools of lettuces [121] for leafy greens, from five chive [61] to 18 asparagus samples [19], and one pool of carrots [37] to 109 pools of cucumbers [94] for roots and other types of fresh produce, from three coriander [37] to 16 Chrysanthemum coronarium samples for herbs [19], and from two pools of raspberries or blueberries [37] to 120 pools of strawberries for fruit [119]. Moreover, six [37] to 648 mixed salad samples were analyzed [120]. In general, the sample amount ranged from one to 20 units or 35 to $3600 \mathrm{~g}$. Since no validation data of the detection methods used for pooled samples were reported, pooling may also have influenced the sensitivity of the detection assays.

Seasonal oocyst detection rates were reported in a few studies on fresh produce with inconclusive results. One study reported a higher detection rate in autumn compared to summer in Switzerland [121], while others reported higher detection rates in samples collected in summer [19,120] or in autumn/winter [37], but in most of these studies, there were no significant differences in detection rates. As discussed previously, extreme weather effects should be also recorded.

Altogether, four articles specified the type of production, and T. gondii was detected in both organic and conventional fresh produce $[37,52,61,118]$. One study performed statistical analysis and reported no significant differences between the two types of production [37]. Similarly, no significant differences were reported between conventional and organic samples in a recent study performed in the United States [154]. Moreover, the sampling locations were diverse, and $T$. gondii was detected in samples collected from open fields, community fairs, storage, local markets, farmlands, school restaurants, and supermarkets $[19,37,52,61,92,118]$. A relevant issue that could favor or hamper oocyst contamination through cat feces may be growing the vegetables in open fields vs. in greenhouses. Unfortunately, although a greenhouse origin was recorded for one study [19], whether the vegetables were grown in open fields or in greenhouses was not specified in other studies.

Data on water sources, irrigation systems, and types of fertilization was limited or not provided in studies included here. Nevertheless, these variables have been identified as relevant risk factors for other foodborne pathogens and may explain some figures reported by the EFSA [155]. A study from the Czech Republic specified that vegetables were irrigated with water from rivers, lakes, or wells and washed with water from the distribution system or wells [94]. Another study from Egypt also stated that the vegetables were irrigated with water from river canals [95]. Water samples were tested in both studies, and T. gondii was detected in one of them [95], while oocysts were detected in fresh produce in both cases (Table 3). The presence of T. gondii oocysts in soil and surface water used for fresh produce production and processing (including packinghouse operations) suggests that there may be a risk of contamination of these products, as previously reported for Cryptosporidium spp. and G. duodenalis in the fresh produce industry [156]. Organic fertilizer (compost/sludge/manure) might not pose a major risk for T. gondii since cat feces are not usually used as fertilizer. In contrast, it is likely that access of cats to crops and weather events spreading oocysts pose a risk for the presence of $T$. gondii oocysts on fresh produce. Thus, oocyst contamination is more unlikely to occur in greenhouses vs. open fields, where the access of cats can be more easily restricted and fresh produce is protected from weather events. One study stated that vegetables grown close to farms are at higher risk of $T$. gondii contamination, which is probably due to the presence of felines [38]. The presence of cats was a variable recorded in four of the selected studies $[38,60,61,88]$, but only two of them reported positive samples [38,61]. 


\subsubsection{Bivalve Mollusks}

Different genera of clams, oysters, and mussels were analyzed worldwide to determine the presence of $T$. gondii. Detection rates varied between 3.6\% (1/28) [139] and 6.6\% (4/61) [140] in pooled clams (Ruditapes decussatus) from Italy and Tunisia, respectively, $1.3 \%(2 / 160)$ [54] and 31.0\% (446/1440) [55] in different species of pooled or individual oysters (Crassostrea spp.) from Brazil and the United States, 1.4\% (13/959) [22] and 46.3\% (19/41) [53] in individual samples of different species of mussels (Mytilus spp.) from the United States, and 3.1\% (3/96) in pooled zebra mussels (Dreissena polymorpha) from France [136] and 12.5\% (13/104) in individual samples of New Zealand mussels (Perna canaliculus) from New Zealand [23] (Table 4, Supplementary Table S5).

It has been reported that filtering activity is multifactorial and affected by bivalve genera, variations in salinity (fluctuates more in coastal marine areas), temperature, level of contamination, and kinetics of parasite diffusion, among other factors [18]. In the studies reviewed here, the same genera of bivalves were collected in different parts of the world, in different locations (coastal, bay or beach, farms and depuration plants, markets/outlets, water treatment plant discharge points), seasons, and at different depths. Moreover, there were other variations in sampling, e.g., pooled samples vs. individual samples, and different tissues selected for oocyst detection. This variation hampers comparisons between studies.

Regarding sampling location, detection rates varied from 1.4\% (13/959) in Mytilus californianus samples [22] to $31.0 \%(446 / 1440)$ in Crassostrea virginica [55] samples from coastal sites in the United States, $1.3 \%(2 / 160)$ [54] to $16.6 \%$ (1/6) [139] in pools of Crassostrea spp. from farms in Brazil and Italy, respectively, 2.5\% (55/2215) to $12.5 \%(13 / 104)$ in individual samples of Mytilus edulis [134] and Perna canaliculus [23] from markets/outlets in China and New Zealand, respectively, and 3.1\% (3/96) in pools of Dreissena polymorpha from different discharge points of wastewater treatment plants in France [136]. The latter study was the only one that documented the depth of the sample collection, which was $20-100 \mathrm{~cm}$. The results from the coastal sites may be influenced by several aspects, including seasonality, human settlements due to the presence of domestic cats, and industrial wastewater. Proximity to freshwater runoff has been associated with the presence of pathogens, including T. gondii, in bivalves [117].

In relation to seasonality, T. gondii oocyst contamination in bivalves was more frequent in spring and autumn compared to other seasons in Italy [138], in summer compared to winter in New Zealand [23], and during the wet season in the United States [22,117]. This could be explained by region-specific weather patterns in each country, so that higher contamination coincides with the rainy season. Extended dry periods may lead to a greater accumulation of oocysts on land that can be mobilized into runoff in subsequent periods of heavy rainfall.

The anatomical regions analyzed were documented in some articles that investigated the presence of $T$. gondii based on molecular assays, but few of them reported the positive samples by tissue type. Most studies analyzed the digestive glands, followed by gills and the hemolymph (Table 4). The digestive glands and hemolymph seem to be appropriate target organs according to the few spiking studies done. Toxoplasma gondii was most often detected in digestive glands compared with hemolymph or gills after experimental contamination under laboratory conditions carried out in mussels [157]. In a later experimental infection done in zebra mussels followed by a depuration process, the greatest concentrations of $T$. gondii DNA were observed in hemolymph and mantle tissues [158]. In field studies, there is evidence that oocysts are more frequently detected in the digestive system and/or hemolymph than in the gills $[134,141]$. However, other studies only found positive gills $[54,139]$ or a higher frequency of positive gills compared to digestive samples [131]. Thus, the three tissues, or at least gills and digestive glands, should be analyzed independently or in pools to optimize parasite detection, since oocyst concentration may vary in these tissues with time post-infection [157]. Indeed, it is recommended to pool the gills and digestive tract, since this strategy optimizes parasite detection in mussels and clams based on the literature published in the presence of T. gondii, as well as Cryp- 
tosporidium spp. and G. duodenalis, in marine mollusks [18]. Conversely, other researchers suggest the use of hemolymph instead of all tissues due to the presumed presence of lower levels of inhibitors and less viscous material, which may improve the sensitivity of the technique [22].

Another important sampling variable is the number of samples analyzed, which varied from 41 [53] to 2215 [134] samples, and from 53 [141] to 208 [131] pools composed of three [131] to 30 [139] units per pool. On the other hand, only a handful of articles $(n=3)$ reported the length of the samples collected, which were longer than $5 \mathrm{~cm}$ in the case of Mytilus galloprovincialis, with similar detection rates in two studies, 10.5\% (43/409) of individual samples [137] and 9.4\% (5/53) of pools [141], and 18-25 mm in the case of Dreissena polymorpha, with $3.1 \%$ (3/96) of positive pools [136].

None of the studies determined the relationship between the presence of oocysts in bivalves and human toxoplasmosis cases caused by their consumption. There is no estimate of the number of $T$. gondii outbreaks associated with consumption of shellfish, including bivalves. According to a study performed in the United States, the consumption of raw oysters, clams, and mussels was identified as a risk for recent $T$. gondii infection $(\mathrm{OR}=2.22$, 95\% CLs 1.07-4.61) [159].

Although the viability of the oocysts detected is unknown, and the only attempt to isolate $T$. gondii by mouse bioassay was not successful [130], bivalves cannot be ruled out as a potential source of infection to humans when they are consumed raw or undercooked. Moreover, it was previously suggested that the sampling strategy should focus on edible mollusk species raised under controlled conditions to better estimate the load and infectivity of filtered parasites that may pose a risk for consumers [18].

\subsection{Toxoplasma gondii Oocyst Detection Methodology}

A lack of harmonized methods for detecting T. gondii oocysts was observed in all environmental matrices (Tables 1-4), and it has been extensively discussed for fresh produce [9]. This issue is supported by the high degree of heterogeneity reported in Section 3.3, and it is also reflected in the range of analytical sensitivities reported for the detection of spiked oocysts in environmental samples in a limited number of studies. In soil samples, ranges of 10-1000 oocysts or 5-50 tachyzoites could be detected in 1 to $300 \mathrm{~g}$ by PCR, qPCR, and nPCR $[12,66,79]$. The analytical sensitivity in water was $1-1000$ oocysts per L by PCR and qPCR $[90,97,98]$. In the case of fresh vegetable samples, the sensitivity reported was 10 oocysts per $30 \mathrm{~g}$ of sample [119], and the number of spiked oocysts detected in bivalve tissues was in the range of 5-1000 oocysts in hemolymph per $\mathrm{mL}$ or sample by $\mathrm{nPCR}[22,23]$ and 100 oocysts in gill tissue by real-time PCR [53].

The recovery of $T$. gondii oocysts and parasite detection are two key sequential steps. Higher variability among different matrices was observed regarding oocyst recovery compared with oocyst detection methods. In fresh produce and bivalve mollusks, a first key point for oocyst recovery was the sampling of individual vs. pooled samples. The analysis of pooled samples may facilitate oocyst detection [120,139], but the recovery and detection methods should be standardized in order to determine the maximum number of samples included in the pool to detect the minimum number of oocysts established by spiking assays. Accordingly, spiking experiments are highly recommended to evaluate the oocyst recovery rate as well as PCR analytical sensitivity and specificity in these complex matrices.

Second, the most extensively used recovery methods for soil and fresh produce were a combination of washing and centrifugation steps that may also include filtration or flotation. Large volumes can be a limiting factor, and filtration has been suggested for fresh produce when working with large volumes of wash buffer or samples [9]. Filtration was the preferred method for water and bivalve samples in combination with centrifugation and/or flotation, although the direct analysis of samples, without a previous oocyst recovery/concentration procedure, was also frequent in bivalves (Tables 1-4). A filtrationcentrifugation method is the basis of the official USEPA method 1623 recommended by the U.S. Environmental Protection Agency (EPA) to evaluate waterborne parasites, such 
as Cryptosporidium spp. and G. duodenalis, in drinking water. However, this method also includes an immunomagnetic separation (IMS) step with specific commercial antibodies. A few specific polyclonal antibodies directed against $T$. gondii oocyst wall components have been generated that could be used for this purpose $[160,161]$, but unfortunately, there is no commercially available anti-T. gondii oocyst antibody. Although several IMS methods have been developed [162,163], improvement of the recovery rate with IMS needs to be demonstrated for environmental matrices [18]. A recent study has achieved a proof-of-principle method for oocyst capture and separation from water using lectin magnetic separation that was later followed by qPCR, and this could be considered in future studies [164].

Recovery efficiency can be also influenced by the formation of foam that can be a challenge in handling fresh produce matrices rich in saponins [9]. It is unclear how different buffers employed for oocyst recovery could work with the different matrices and with the different mixes of vegetables analyzed. Thus, the avoidance of detergents in washing buffers (at least for fresh produce) should be considered. In order to confirm the use of appropriate buffers and efficient separation methods, spiking experiments with oocysts should be done in order to maximize the efficiency of oocyst recovery during the method standardization process [165].

Regarding detection methods, PCR was extensively employed and predominated vs. microscopy and bioassay methods (Tables 1-4). The sensitivity of different PCR techniques can be influenced by the different assays used to rupture the robust oocyst wall, the presence of PCR inhibitors, and the PCR protocols/procedures. Different methods to achieve efficient rupture of the oocyst wall such as bead beating, ultrasound, and freeze-and-thaw have been discussed [9], and many of the PCR-based studies reviewed here described the use of freeze-and-thaw or bead beating prior to DNA extraction that may increase analytical sensitivity [9]. In addition, the inclusion of an internal DNA amplification control (IAC) is recommended [9], as the presence of PCR inhibitors has been reported in soil, water (e.g., organic material), fresh produce, and bivalves, and IAC is mandatory for the detection of foodborne pathogens according to ISO 22174: 2005. It was rare for studies to report the use of an IAC (soil: [12,81], water: [109], fresh produce: [19,94], bivalves: [139]). Instead, some studies used commercial kits that included an appropriate PCR inhibitor removal step [53] or bovine serum albumin (BSA) $[50,63,66,69,72,97,98,109]$, but the inhibition problem was not always solved.

DNA amplification methods (conventional PCR, nested PCR, qPCR, LAMP) targeted either B1, SAG1, 18sRNA, ITS-1, MIC3, GRA6, and 529RE markers [9]. The most commonly employed marker was B1 (in water, fresh produce, and bivalves) followed by 529RE (in soil), and a combination of both. This finding can be easily explained by the fact that sensitivity is increased when targeting multi-copy loci (B1, $529 \mathrm{RE}$, and ITS1) compared with singlecopy gene targets (e.g., SAG1 and GRA6), as shown previously [22]. These PCR methods display high sensitivity but might lack in specificity as previously evidenced [22,166]. In fact, qPCR targeting the B1 gene and 529RE without probes cross-reacted with Sarcocystidae members [167]. Thus, powerful discrimination techniques are necessary to avoid false positive results and confirm species identity [22,37,121]. In this regard, the use of TaqMan probes in qPCR guarantees high specificity [9]. Alternative methods should be also taken into consideration. Amplicon sequencing and Restriction Fragment Length Polymorphism (RFLP) analyses have been used in some of the studies to confirm positive results (Tables 1-4, Supplementary Tables S2-S5).

Toxoplasma gondii genotyping could help not only to confirm results but also to identify circulating genotypes. Genotyping tools (PCR-RFLP, microsatellite typing, PCR sequencing) were applied for this purpose in some studies, but in some instances, they were unsuccessful $[19,119]$ or results were not reliable (e.g., based on a single marker [168]). The low oocyst burden observed in the environmental matrices (Supplementary Tables S2-S5) could limit the success of typing methods $[169,170]$. Currently, it is accepted that if samples are not fully characterized at the genotype level (https:/ / toxodb.org/, accessed on 1 January 2022), the information gathered is not reliable enough for drawing robust conclu- 
sions [171,172]. Indeed, literature reviews have shown the low reliability of molecular data from environmental samples [8,172], since an unexpectedly high proportion of genotype I and non-canonical strains have been reported, which contrasts with the findings in samples from other sources such as domestic animals and humans from the same areas [172]. Therefore, additional efforts should be invested into unraveling the genotypes circulating in environmental matrices following an accurate and commonly accepted approach.

Finally, parasite quantification was not routinely carried out and was only estimated in a few studies conducted on soil, fresh produce, and bivalves. The limited data reported on parasite quantification were variable, as parasite load was referred to as the number of oocysts per $\mathrm{g}$, per sample, per $\mathrm{mL}$ or $\mu \mathrm{L}$, per DNA volume, or tachyzoite-equivalent copies. The quantity of T. gondii oocysts in soil varied from 11 to 2275 oocysts per mL [57] and 8 to 478 oocysts per $30 \mathrm{~g}$ of sample [81]. In fresh produce, the ranges were 1.31-900 oocysts per $g$ of sample [94], 62-554 oocysts per g of vegetable matter [120], 0.6-179.9 oocysts (mean of $23.5 \pm 12.1$ oocysts per $\mathrm{g}$ ) [37], <10-20 oocysts per sample (mean of three oocysts per sample) [38], and 0.3-27,640 oocysts per sample [19]. On the other hand, in bivalves, it ranged from 6 to 30 oocysts per sample [141] or per $5 \mu \mathrm{L}$ of DNA [102], 1250 to 77,500 oocysts per sample $(x=24,694, \mathrm{SEM}=14,254.5)$ [140], 0.001 to 219 copies per $\mu \mathrm{L}$ of DNA [55], and 0.14 to 1.18 copies per $\mathrm{g}$ [137]. Means of 40-546 tachyzoite equivalents per $\mathrm{mL}$ were reported [139], as were Ct means of 39.1-40.7, which were equivalent to 0.1-1.4 oocysts [136]. However, the effect of matrix, as well as the effect of the performance of the reagents used and the lack of validation of the procedures, make the quantification questionable. Despite these variable results, parasite load was occasionally very high in the three matrices. Ideally, in this scenario, parasite viability should be estimated to define more clearly the risk that these matrices pose for humans.

Viability assays can be employed as detection methods and mouse bioassay has been suggested as a reference test for parasite detection, as mice are highly susceptible species to T. gondii infection [173]. In addition, bioassay methods can help to check the infectivity of the oocysts, and mouse bioassay has been widely employed for this purpose. The analysis of the literature evidenced that 15 of the studies attempted to isolate viable parasites mainly by bioassay in mice but also in pigs, chickens, and cats, and 11 obtained positive results (Tables 1-4, Supplementary Tables S2-S5). Although standardized bioassay methods are needed [173], due to ethical concerns, new alternative techniques are required to discriminate between viable and inactivated oocysts. To date, there are some new proposals to estimate oocysts viability: propidium monoazide coupled with qPCR [29,31], staining with propidium iodide [31], reverse transcription quantitative PCR (RT-qPCR) [31,174], reverse transcription PCR (RT-PCR), excystation and dyes [175], and cell culture after oocysts excystation [174]. However, further studies are necessary to standardize these processes for different matrices and guarantee their correct performance.

\section{Conclusions and Considerations for Future Research}

The worldwide detection rates reported for the different environmental matrices covered in this systematic review, together with the published reports of confirmed human toxoplasmosis outbreaks due to contaminated soil, water, and fresh produce, provide evidence that environmental contamination with $T$. gondii oocysts poses a risk to public health. This is supported by the oocyst load/burden detected in different studies, which should not be underestimated given the fact that a single oocyst can cause infection, and that oocysts can persist in the environment for months or years, including in the marine environment [31]. Moreover, environmental oocyst contamination is a major source of infection for animal hosts, including animal hosts raised and hunted for human consumption [176-178]. This exemplifies that T. gondii is a pathogen that needs to be addressed using a One Health approach.

The timeline of the studies conducted on the different matrices is noteworthy. Fresh produce has been investigated only recently, and the number of studies is still limited. The timeline appears to be in line with the increasingly understood importance of other food- 
and waterborne zoonotic protists, in particular Cryptosporidium spp. Geographical gaps were also evident; many areas of the world of the world are significantly underrepresented in the studies: for example, sub-Saharan Africa. The overall detection rates of T. gondii were highly variable for each matrix, which can be partially explained by the different sampling strategies and methodologies employed. Differences in T. gondii detection in fresh produce have been attributed to variables such as the geographical location and methods used for parasite detection $[9,33]$, which could also apply to other environmental matrices. Thus, it is important to consider both the sampling strategy and the methodology, as they can potentially influence parasite detection success and hamper comparisons between different studies. Regarding the sampling strategy, sampling areas, sample type, number, and mass or volume must be based on previous studies and available data such as reported toxoplasmosis cases in humans and animals, reported detection rates in environmental samples, expected detection rates, variability, and others. Regarding methodologies employed for environmental matrices, the most crucial steps to be considered are the spiking assays and the inclusion of an IAC to validate the recovery and detection methods. This would enable an estimation of analytical sensitivity and specificity and avoid false negatives results so that correct interpretation of the results would be guaranteed. Well-documented and standardized bioassays and genotyping methods will also help to determine the risk of exposure and how T. gondii circulates in the environment. Unfortunately, consensus guidelines have not yet been proposed by the scientific community. In the meantime, it would be advisable to include as much information as possible in publications, including details of experimental design and methodology.

More studies on T. gondii in environmental matrices are needed, and the focus should be on the gaps identified in this review. The impact of water contamination can be high, since its consumption is not limited by eating habits, as happens for vegetarians with meat-borne toxoplasmosis cases. In addition, water can contaminate soil, seafood, or fresh produce. Significant detection rates were found in surface water, in samples collected after a long treatment process, in irrigation/washing, and potable water. Moreover, the survival of oocysts in soil and the widespread consumption of minimally processed fresh produce and bivalves support the recommendation that T. gondii, as well as other cyst/oocyst forming protist parasites, should be included in regular food and water quality control guidelines within the food sector. Meanwhile, basic measures should be adopted by consumers such as washing of hands after handling soil or cat feces, washing fresh produce with clean water regardless of product presentation, and proper cooking of bivalves.

Altogether, the relative contribution of different environmental matrices as T. gondii sources of infection to humans and animals remains unknown. Baseline data for risk assessment are limited and challenging to compare, since results may be influenced by sampling and methodological variables. Moreover, risk factors have not been adequately addressed in the context of the whole food chain including agricultural production and processing (incorporating soil, water, fresh produce including RTE products, and bivalves) given the limited and heterogeneous literature published. As an example, future work should investigate oocyst detection at the different steps of the RTE production workflow to implement mitigation strategies that might also help to avoid contamination with a wide variety of protozoa, helminths, fungi, and insects [179] and reduce infection risk for humans. Surveillance studies should ideally be accompanied by viability and genotyping assays to accurately determine the potential risk for consumers and enable tracing the sources. In general, all gaps identified evidenced the need to implement standardized procedures that could help to establish an ISO method and harmonize future studies focusing on environmental matrices. In Figure 3, we summarize the key aspects that should be considered when designing and implementing a study investigating T. gondii contamination of environmental matrices. As a minimum, these aspects should be explicitly addressed when reporting on the outcomes of such a study. Additional data to be considered could be extracted from systematic reviews and meta-analyses of risk factors for human infection with T. gondii (e.g., [180-182]). Similarly, the present review could also help further meta- 
analyses of risk factors in humans to identify relevant data. We appreciate the challenge of designing an adequately powered study, taking into account the multiple factors we have highlighted that can influence oocyst detection in environmental matrices. However, through the implementation of well-designed studies in the future, it will be possible to assess the contribution of different environmental matrices as sources of T. gondii infection to humans and animals and provide appropriate advice to policy makers, food producers, and consumers.

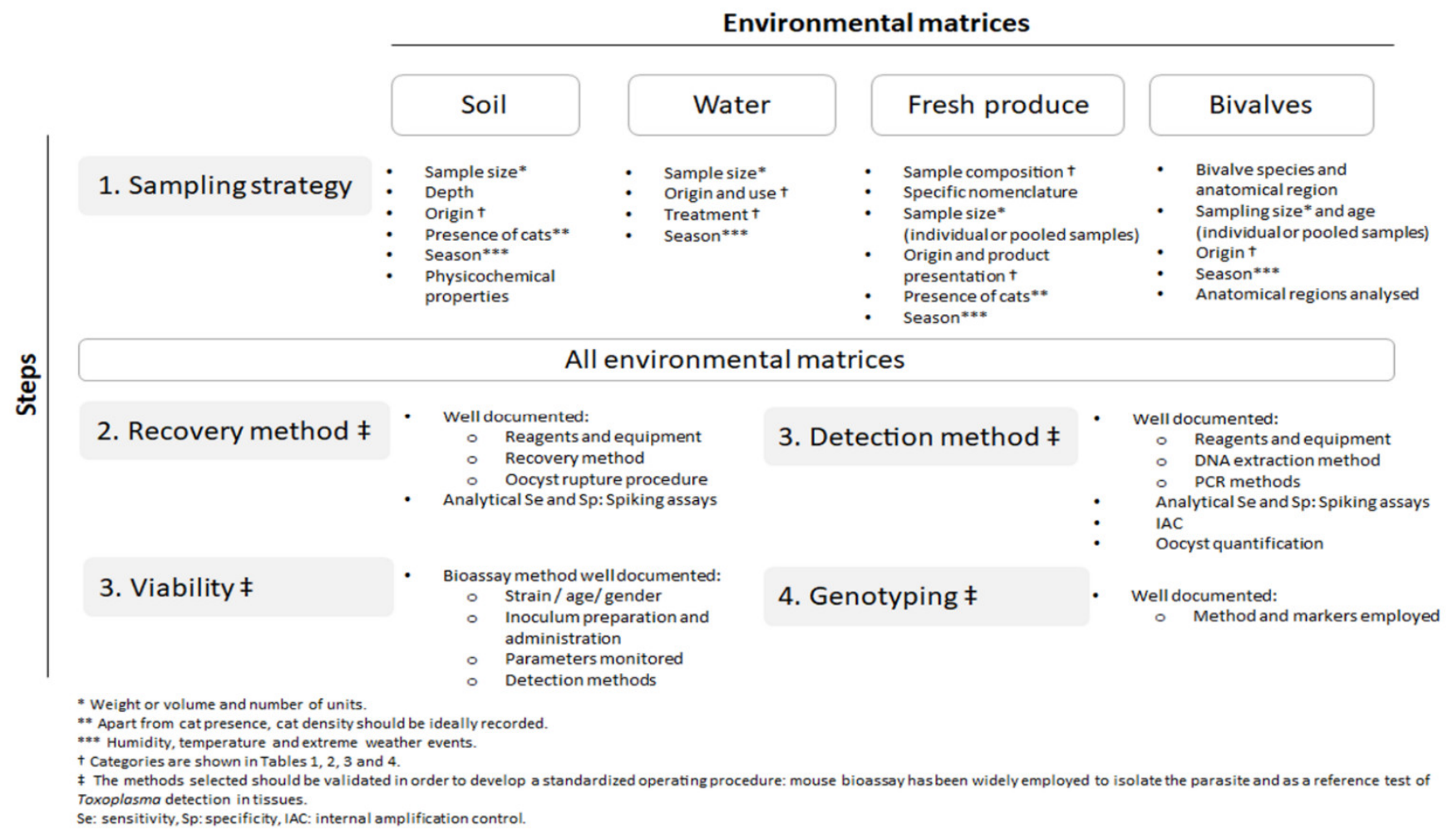

Figure 3. Workflow and key considerations for standard sampling strategies and detection methods for Toxoplasma gondii in environmental matrices.

Supplementary Materials: The following are available online at https: / www.mdpi.com/article / 10.3390/microorganisms10030517/s1, Supplementary Figures S1-S4 (Forest plots for each matrix), Supplementary Figure S5 (Funnel plots for each matrix) and Supplementary Tables S1-S5: Excel file with the list of papers selected from each database and combination of search terms (Supplementary Table S1) and detailed data extracted from articles on soil (Supplementary Table S2), water (Supplementary Table S3), fresh produce (Supplementary Table S4), and bivalve mollusks (Supplementary Table S5).

Author Contributions: G.Á.G., P.J. and M.L. conceived the study; N.M.L.U. and G.Á.G. coordinated and organized the systematic review; N.M.L.U., D.M. and F.E. surveyed the literature; N.M.L.U., D.M. and F.E. collected and selected the articles; N.M.L.U., U.C., R.C.B., M.B. and G.Á.G. extracted and reviewed the data; N.M.L.U., U.C., R.C.B., M.B. and G.Á.G. drafted the manuscript; N.M.L.U., U.C., R.C.B., M.B. and G.Á.G. designed tables and figures; S.C.A. performed the statistical analysis; N.M.L.U., U.C., R.C.B., S.C.A., D.M., F.E., M.B., M.L., P.J., L.M.O.M. and G.Á.G. reviewed and edited the manuscript. All authors have read and agreed to the published version of the manuscript.

Funding: This study was part of TOXOSOURCES project, supported by funding from the European Union's Horizon 2020 Research and Innovation programme under grant agreement No. 773830: One Health European Joint Programme. Publication costs are covered by the same grant. Nadia María López Ureña is sponsored by the 2018-2019 predoctoral fellowship UCM/Santander.

Institutional Review Board Statement: Not applicable. 


\section{Informed Consent Statement: Not applicable.}

Data Availability Statement: The present review has not been registered. All data collected and systematically searched are available in the Supplementary Tables provided.

Acknowledgments: To TOXOSOURCES project, supported by funding from the European Union's Horizon 2020 Research and Innovation programme under grant agreement No. 773830: One Health European Joint Programme and all TOXOSOURCES collaborators.

Conflicts of Interest: M.L. is guest editor for Microorganisms, Special Issue "Advances in the Diagnosis, Detection, Epidemiology, and Control of Toxoplasma gondii", but he had no role in the editorial handling of the current manuscript. The other authors declare no conflict of interest.

\section{References}

1. Weiss, L.M.; Dubey, J.P. Toxoplasmosis: A History of Clinical Observations. Int. J. Parasitol. 2009, 39, 895-901. [CrossRef] [PubMed]

2. Marstrand, J.; Kurtzhals, J.A.L.; Fuchs, H.J.; Nielsen, H.V.; Jokelainen, P. The Disease Burden of Ocular Toxoplasmosis in Denmark in 2019: Estimates Based on Laboratory Testing of Ocular Samples and on Publicly Available Register Data. Parasite Epidemiol. Control 2021, 15, e00229. [CrossRef] [PubMed]

3. Eza, D.E.; Lucas, S.B. Fulminant Toxoplasmosis Causing Fatal Pneumonitis and Myocarditis. HIV Med. 2006, 7, 415-420. [CrossRef] [PubMed]

4. Jokelainen, P.; Simola, O.; Rantanen, E.; Näreaho, A.; Lohi, H.; Sukura, A. Feline Toxoplasmosis in Finland: Cross-Sectional Epidemiological Study and Case Series Study. J. Vet. Diagn. Investig. 2012, 24, 1115-1124. [CrossRef] [PubMed]

5. Bowen, L.N.; Smith, B.; Reich, D.; Quezado, M.; Nath, A. HIV-Associated Opportunistic CNS Infections: Pathophysiology, Diagnosis and Treatment. Nat. Rev. Neurol. 2016, 12, 662-674. [CrossRef]

6. Robertson, L.J.; Lalle, M.; Paulsen, P. Why We Need a European Focus on Foodborne Parasites. Exp. Parasitol. 2020, 214, 107900. [CrossRef]

7. Shapiro, K.; Bahia-Oliveira, L.; Dixon, B.; Dumètre, A.; de Wit, L.A.; VanWormer, E.; Villena, I. Environmental Transmission of Toxoplasma gondii: Oocysts in Water, Soil and Food. Food Waterborne Parasitol. 2019, 15, e00049. [CrossRef]

8. Almeria, S.; Dubey, J.P. Foodborne Transmission of Toxoplasma gondii Infection in the Last Decade. An Overview. Res. Vet. Sci. 2021, 135, 371-385. [CrossRef]

9. Slana, I.; Bier, N.; Bartosova, B.; Marucci, G.; Possenti, A.; Mayer-Scholl, A.; Jokelainen, P.; Lalle, M. Molecular Methods for the Detection of Toxoplasma gondii Oocysts in Fresh Produce: An Extensive Review. Microorgonisms 2021, 9, 167. [CrossRef]

10. Attias, M.; Teixeira, D.E.; Benchimol, M.; Vommaro, R.C.; Crepaldi, P.H.; De Souza, W. The Life-Cycle of Toxoplasma gondii Reviewed Using Animations. Parasites Vectors 2020, 13, 1-13. [CrossRef]

11. Dumètre, A.; Dardé, M.-L.L. How to Detect Toxoplasma gondii Oocysts in Environmental Samples? FEMS Microbiol. Rev. 2003, 27, 651-661. [CrossRef]

12. Simon, J.A.; Kurdzielewicz, S.; Jeanniot, E.; Dupuis, E.; Marnef, F.; Aubert, D.; Villena, I.; Poulle, M.L. Spatial Distribution of Soil Contaminated with Toxoplasma gondii Oocysts in Relation to the Distribution and Use of Domestic Cat Defecation Sites on Dairy Farms. Int. J. Parasitol. 2017, 47, 357-367. [CrossRef] [PubMed]

13. Bowie, W.R.; King, A.S.; Werker, D.H.; Isaac-Renton, J.L.; Bell, A.; Eng, S.B.; Marion, S.A. Outbreak of Toxoplasmosis Associated with Municipal Drinking Water. The BC Toxoplasma Investigation Team. Lancet 1997, 350, 173-177. [CrossRef]

14. Pinto-Ferreira, F.; Caldart, E.T.; Pasquali, A.K.S.; Mitsuka-Breganó, R.; Freire, R.L.; Navarro, I.T. Patterns of Transmission and Sources of Infection in Outbreaks of Human Toxoplasmosis. Emerg. Infect. Dis. 2019, 25, 2177-2182. [CrossRef] [PubMed]

15. Wainwright, K.E.; Miller, M.A.; Barr, B.C.; Gardner, I.A.; Melli, A.C.; Essert, T.; Packham, A.E.; Truong, T.; Lagunas-Solar, M.; Conrad, P.A. Chemical Inactivation of Toxoplasma gondii Oocysts in Water. J. Parasitol. 2007, 93, 925-931. [CrossRef] [PubMed]

16. Mirza Alizadeh, A.; Jazaeri, S.; Shemshadi, B.; Hashempour-Baltork, F.; Sarlak, Z.; Pilevar, Z.; Hosseini, H. A Review on Inactivation Methods of Toxoplasma gondii in Foods. Pathog. Glob. Health 2018, 112, 306-319. [CrossRef] [PubMed]

17. Dubey, J.P. Toxoplasmosis-A Waterborne Zoonosis. Vet. Parasitol. 2004, 126, 57-72. [CrossRef]

18. Hohweyer, J.; Dumètre, A.; Aubert, D.; Azas, N.; Villena, I. Tools and Methods for Detecting and Characterizing Giardia, Cryptosporidium, and Toxoplasma Parasites in Marine Mollusks. J. Food Prot. 2013, 76, 1649-1657. [CrossRef]

19. Lass, A.; Ma, L.; Kontogeorgos, I.; Zhang, X.; Li, X.; Karanis, P. First Molecular Detection of Toxoplasma gondii in Vegetable Samples in China Using Qualitative, Quantitative Real-Time PCR and Multilocus Genotyping. Sci. Rep. 2019, 9, 1-11. [CrossRef]

20. Barhoumi, B.; Lemenach, K.; Devier, M.H.; Ameur, W.B.; Etcheber, H.; Budzinski, H.; Cachot, J.; Driss, M.R. Polycyclic Aromatic Hydrocarbons (PAHs) in Surface Sediments from the Bizerte Lagoon, Tunisia: Levels, Sources, and Toxicological Significance. Environ. Monit. Assess. 2014, 186, 2653-2669. [CrossRef]

21. Miller, M.A.; Miller, W.A.; Conrad, P.A.; James, E.R.; Melli, A.C.; Leutenegger, C.M.; Dabritz, H.A.; Packham, A.E.; Paradies, D.; Harris, M.; et al. Type X Toxoplasma gondii in a Wild Mussel and Terrestrial Carnivores from Coastal California: New Linkages between Terrestrial Mammals, Runoff and Toxoplasmosis of Sea Otters. Int. J. Parasitol. 2008, 38, 1319-1328. [CrossRef] [PubMed] 
22. Shapiro, K.; Vanwormer, E.; Aguilar, B.; Conrad, P.A. Surveillance for Toxoplasma gondii in California Mussels (Mytilus californianus) Reveals Transmission of Atypical Genotypes from Land to Sea. Environ. Microbiol. 2015, 17, 4177-4188. [CrossRef] [PubMed]

23. Coupe, A.; Howe, L.; Burrows, E.; Sine, A.; Pita, A.; Velathanthiri, N.; Vallée, E.; Hayman, D.; Shapiro, K.; Roe, W.D. First Report of Toxoplasma gondii Sporulated Oocysts and Giardia duodenalis in Commercial Green-Lipped Mussels (Perna canaliculus) in New Zealand. Parasitol. Res. 2018, 117, 1453-1463. [CrossRef] [PubMed]

24. Lindsay, D.S.; Collins, M.V.; Mitchell, S.M.; Wetch, C.N.; Rosypal, A.C.; Flick, G.J.; Zajac, A.M.; Lindquist, A.; Dubey, J.P. Survival of Toxoplasma gondii Oocysts in Eastern Oysters (Crassostrea virginica). J. Parasitol. 2004, 90, 1054-1057. [CrossRef] [PubMed]

25. Palos-Ladeiro, M.; Bigot, A.; Aubert, D.; Hohweyer, J.; Favennec, L.; Villena, I.; Geffard, A. Protozoa Interaction with Aquatic Invertebrate: Interest for Watercourses Biomonitoring. Environ. Sci. Pollut. Res. Int. 2013, 20, 778-789. [CrossRef]

26. Dabritz, H.A.; Conrad, P.A. Cats and Toxoplasma: Implications for Public Health. Zoonoses Public Health 2010, 57, 34-52. [CrossRef]

27. Remes, N.; Kärssin, A.; Must, K.; Tagel, M.; Lassen, B.; Jokelainen, P. Toxoplasma gondii Seroprevalence in Free-Ranging Moose (Alces alces) Hunted for Human Consumption in Estonia: Indicator Host Species for Environmental Toxoplasma gondii Oocyst Contamination. Vet. Parasitol. Reg. Stud. Rep. 2018, 11, 6-11. [CrossRef]

28. Álvarez-García, G.; Davidson, R.; Jokelainen, P.; Klevar, S.; Spano, F.; Seeber, F. Identification of Oocyst-Driven Toxoplasma gondii Infections in Humans and Animals through Stage-Specific Serology-Current Status and Future Perspectives. Microorganisms 2021, 9, 2346. [CrossRef]

29. Rousseau, A.; Villena, I.; Dumètre, A.; Escotte-Binet, S.; Favennec, L.; Dubey, J.P.; Aubert, D.; La Carbona, S. Evaluation of Propidium Monoazide-Based QPCR to Detect Viable Oocysts of Toxoplasma gondii. Parasitol. Res. 2019, 118, 999-1010. [CrossRef]

30. Marciano, M.A.M.; Silva, R.A.; Barbosa, M.L.; Ferreira, A.R.S.; Pereira-Chioccola, V.L. Determination of the Viability of Toxoplasma gondii Oocysts by PCR Real-Time after Treatment with Propidium Monoazide. Rev. Inst. Med. Trop. 2020, 62, e84. [CrossRef]

31. Kim, M.; Shapiro, K.; Rajal, V.B.; Packham, A.; Aguilar, B.; Rueda, L.; Wuertz, S. Quantification of Viable Protozoan Parasites on Leafy Greens Using Molecular Methods. Food Microbiol. 2021, 99, 103816. [CrossRef] [PubMed]

32. Kakakhel, M.A.; Wu, F.; Anwar, Z.; Saif, I.; Akbar, N.u.; Gul, N.; Ali, I.; Feng, H.; Wang, W. The Presence of Toxoplasma gondii in Soil, Their Transmission, and Their Influence on the Small Ruminants and Human Population: A Review. Microb. Pathog. 2021, 158, 104850. [CrossRef] [PubMed]

33. Berrouch, S.; Escotte-Binet, S.; Harrak, R.; Huguenin, A.; Flori, P.; Favennec, L.; Villena, I.; Hafid, J. Detection Methods and Prevalence of Transmission Stages of Toxoplasma gondii, Giardia duodenalis and Cryptosporidium spp. in Fresh Vegetables: A Review. Parasitology 2020, 147, 516-532. [CrossRef]

34. Maleki, B.; Ahmadi, N.; Olfatifar, M.; Gorgipour, M.; Taghipour, A.; Abdoli, A.; Khorshidi, A.; Foroutan, M.; Mirzapour, A. Toxoplasma Oocysts in the Soil of Public Places Worldwide: A Systematic Review and Meta-Analysis. Trans. R Soc. Trop. Med. Hyg. 2021, 115, 471-481. [CrossRef]

35. Nayeri, T.; Sarvi, S.; Daryani, A. Toxoplasma gondii in Mollusks and Cold-Blooded Animals: A Systematic Review. Parasitology 2021, 148, 1-33. [CrossRef] [PubMed]

36. Moher, D.; Liberati, A.; Tetzlaff, J.; Altman, D.G. Preferred Reporting Items for Systematic Reviews and Meta-Analyses: The PRISMA Statement. BMJ 2009, 339, 332-336. [CrossRef] [PubMed]

37. Marques, C.S.; Sousa, S.; Castro, A.; Da Costa, J.M.C. Detection of Toxoplasma gondii Oocysts in Fresh Vegetables and Berry Fruits. Parasites Vectors 2020, 13, 1-12. [CrossRef]

38. Lass, A.; Pietkiewicz, H.; Szostakowska, B.; Myjak, P. The First Detection of Toxoplasma gondii DNA in Environmental Fruits and Vegetables Samples. Eur. J. Clin. Microbiol. Infect. Dis. 2012, 31, 1101-1108. [CrossRef]

39. Higgins, J.P.T.; Thompson, S.G. Quantifying Heterogeneity in a Meta-Analysis. Stat. Med. 2002, 21, 1539-1558. [CrossRef]

40. Gebremedhin, E.Z.; Tadesse, G. A Meta-Analysis of the Prevalence of Toxoplasma gondii in Animals and Humans in Ethiopia. Parasit. Vectors 2015, 8, 291. [CrossRef]

41. Hatam-Nahavandi, K.; Calero-Bernal, R.; Rahimi, M.T.; Pagheh, A.S.; Zarean, M.; Dezhkam, A.; Ahmadpour, E. Toxoplasma gondii Infection in Domestic and Wild Felids as Public Health Concerns: A Systematic Review and Meta-Analysis. Sci. Rep. 2021, 11, 1-11. [CrossRef]

42. Toxosources Deliverable-Work Package 3. 2021. Available online: https://zenodo.org/record/5812067\#.YgjKZd_MI2w (accessed on 31 December 2021).

43. Dubey, J.P. History of the Discovery of the Life Cycle of Toxoplasma gondii. Int. J. Parasitol. 2009, 39, 877-882. [CrossRef] [PubMed]

44. Mac Kenzie, W.R.; Schell, W.L.; Blair, K.A.; Addiss, D.G.; Peterson, D.E.; Hoxie, N.J.; Kazmierczak, J.J.; Davis, J.P. Massive Outbreak of Waterborne Cryptosporidium Infection in Milwaukee, Wisconsin: Recurrence of Illness and Risk of Secondary Transmission. Clin. Infect. Dis. 1995, 21, 57-62. [CrossRef]

45. Hayes, E.B.; Matte, T.D.; O’Brien, T.R.; McKinley, T.W.; Logsdon, G.S.; Rose, J.B.; Ungar, B.L.P.; Word, D.M.; Wilson, M.A.; Long, E.G.; et al. Large Community Outbreak of Cryptosporidiosis Due to Contamination of a Filtered Public Water Supply. N. Engl. J. Med. 1989, 320, 1372-1376. [CrossRef] [PubMed]

46. Mac Kenzie, W.R.; Hoxie, N.J.; Proctor, M.E.; Gradus, M.S.; Blair, K.A.; Peterson, D.E.; Kazmierczak, J.J.; Addiss, D.G.; Fox, K.R.; Rose, J.B.; et al. A Massive Outbreak in Milwaukee of Cryptosporidium Infection Transmitted through the Public Water Supply. N. Engl. J. Med. 1994, 331, 161-167. [CrossRef] 
47. Fayer, R.; Graczyk, T.K.; Lewis, E.J.; Trout, J.M.; Parley, C.A. Survival of Infectious Cryptosporidium parvum Oocysts in Seawater and Eastern Oysters (Crassostrea virginica) in the Chesapeake Bay. Appl. Environ. Microbiol. 1998, 64, 1070-1074. [CrossRef] [PubMed]

48. Liu, X.C.; He, Y.; Han, D.G.; Zhang, Z.C.; Li, K.; Wang, S.; Xu, L.X.; Yan, R.F.; Li, X.R. Detection of Toxoplasma gondii in Chicken and Soil of Chicken Farms in Nanjing Region, China. Infect. Dis. Poverty 2017, 6, 62. [CrossRef] [PubMed]

49. Ito, S.; Tsunoda, K.; Tsutsumi, Y.; Matsui, T.; Nishikawa, H. Detection and Confirmation of Toxoplasma Oocysts in the Soil. Nihon Juigaku Zasshi. 1975, 37, 549-554. [CrossRef]

50. Kourenti, C.; Karanis, P. Evaluation and Applicability of a Purification Method Coupled with Nested PCR for the Detection of Toxoplasma Oocysts in Water. Lett. Appl. Microbiol. 2006, 43, 475-481. [CrossRef]

51. Minuzzi, C.E.; Fernandes, F.D.; Portella, L.P.; Bräunig, P.; Sturza, D.A.F.; Giacomini, L.; Salvagni, E.; Ribeiro, J.d.S.; Silva, C.R.; Difante, C.M.; et al. Contaminated Water Confirmed as Source of Infection by Bioassay in an Outbreak of Toxoplasmosis in South Brazil. Transbound. Emerg. Dis. 2021, 68, 767-772. [CrossRef]

52. Lalonde, L.F.; Gajadhar, A.A. Detection of Cyclospora cayetanensis, Cryptosporidium spp., and Toxoplasma gondii on Imported Leafy Green Vegetables in Canadian Survey. Food Waterborne Parasitol. 2016, 2, 8-14. [CrossRef]

53. Staggs, S.E.; Keely, S.P.; Ware, M.W.; Schable, N.; See, M.J.; Gregorio, D.; Zou, X.; Su, C.; Dubey, J.P.; Villegas, E.N. The Development and Implementation of a Method Using Blue Mussels (Mytilus spp.) as Biosentinels of Cryptosporidium spp. and Toxoplasma gondii Contamination in Marine Aquatic Environments. Parasitol. Res. 2015, 114, 4655-4667. [CrossRef] [PubMed]

54. Silva, C.M.; Silva, A.L.P.; Watanabe, K.F.C.; Bezerra, N.P.C.; Bezerra, D.C.; Gomes, H.M.; Freire, T.B.; Dos Santos, L.S.; de C. Neta, A.V.; Silva, E.M.C.; et al. First Report of Detection of Toxoplasma gondii DNA in Oysters (Crassostrea sp.) in the State of Maranhão. Rev. Bras. Parasitol. Vet. 2020, 29, 1-6. [CrossRef] [PubMed]

55. Marquis, N.D.; Bishop, T.J.; Record, N.R.; Countway, P.D.; Fernández Robledo, J.A. Molecular Epizootiology of Toxoplasma gondii and Cryptosporidium parvum in the Eastern Oyster (Crassostrea virginica) from Maine (USA). Pathogens 2019, 8, 125. [CrossRef]

56. Coutinho, S.G.; Lobo, R.; Dutra, G. Isolation of Toxoplasma from the Soil during an Outbreak of Toxoplasmosis in a Rural Area in Brazil. J. Parasitol. 1982, 68, 866. [CrossRef]

57. Da Silva, R.C.; Langoni, H. Risk Factors and Molecular Typing of Toxoplasma gondii Isolated from Ostriches (Struthio camelus) from a Brazilian Slaughterhouse. Vet. Parasitol. 2016, 225, 73-80. [CrossRef]

58. Dos Santos, T.R.; Nunes, C.M.; Luvizotto, M.C.R.; de Moura, A.B.; Lopes, W.D.Z.; da Costa, A.J.; Bresciani, K.D.S. Detection of Toxoplasma gondii Oocysts in Environmental Samples from Public Schools. Vet. Parasitol. 2010, 171, 53-57. [CrossRef]

59. Felicio, P.; Villalobos, E.; Lara, M.; Cunha, E.; Carvalho, P.; Chiebao, D.; Gabriel, F.; Nassar, A.; Nogueira, A.; Okuda, L.; et al. Eco-Epidemiology of Toxoplasmosis in Ruminant and the Experimental Model of Evidence from Mice Bioassay for Transmission of Infection Starting of Contaminated Soil Samples Confirmed by Polymerase Chain Reaction (PCR) and Indirect Immunofluorescence Reacti. Glob. Vet. 2011, 6, 78-90.

60. Pinto-Ferreira, F.; Mitsuka-Breganó, R.; Monica, T.C.; Martins, F.D.C.; De Matos, L.R.N.; Mareze, M.; Nino, B.D.S.L.; Narciso, S.G.; Freire, R.L.; Navarro, I.T. Investigation and Environmental Analysis of Samples from Outbreak of Toxoplasmosis at Research Institution in Londrina. Electron. Braz. J. Vet. Parasitol 2019, 28, 518-521. [CrossRef]

61. Pinto-Ferreira, F.; Caldart, E.T.; Freire, R.L.; Mitsuka-Breganó, R.; de Freitas, F.M.; Miura, A.C.; Mareze, M.; Martins, F.D.C.; Urbano, M.R.; Seifert, A.L.; et al. The Effect of Water Source and Soil Supplementation on Parasite Contamination in Organic Vegetable Gardens. Rev. Bras. Parasitol. Vet. 2018, 27, 327-337. [CrossRef]

62. Cong, W.; Zhang, N.Z.; Hu, R.S.; Zou, F.C.; Zou, Y.; Zhong, W.Y.; Wu, J.J.; Fallaize, C.J.; Zhu, X.Q.; Elsheikha, H.M. Prevalence, Risk Factors and Genotype Distribution of Toxoplasma gondii DNA in Soil in China. Ecotoxicol. Environ. Saf. 2020, 189, 109999. [CrossRef] [PubMed]

63. Du, F.; Feng, H.L.; Nie, H.; Tu, P.; Zhang, Q.L.; Hu, M.; Zhou, Y.Q.; Zhao, J.L. Survey on the Contamination of Toxoplasma gondii Oocysts in the Soil of Public Parks of Wuhan, China. Vet. Parasitol. 2012, 184, 141-146. [CrossRef] [PubMed]

64. Du, F.; Zhang, Q.; Yu, Q.; Hu, M.; Zhou, Y.; Zhao, J. Soil Contamination of Toxoplasma gondii Oocysts in Pig Farms in Central China. Vet. Parasitol. 2012, 187, 53-56. [CrossRef] [PubMed]

65. Gao, X.; Wang, H.; Wang, H.; Qin, H.; Xiao, J. Land Use and Soil Contamination with Toxoplasma gondii Oocysts in Urban Areas. Sci. Total Environ. 2016, 568, 1086-1091. [CrossRef] [PubMed]

66. Wang, M.; Meng, P.; Ye, Q.; Pu, Y.-H.; Yang, X.-Y.; Luo, J.-X.; Zhang, N.-Z.; Zhang, D.-L. Detection of Toxoplasma gondii Oocysts in Soils in Northwestern China Using a New Semi-Nested PCR Assay. BMC Vet. Res. 2014, 10, 238. [CrossRef]

67. Ruiz, A.; Frenkel, J.K.; Cerdas, L. Isolation of Toxoplasma from Soil. J. Parasitol. 1973, 59, 204-206. [CrossRef]

68. Afonso, E.; Lemoine, M.; Poulle, M.L.; Ravat, M.C.; Romand, S.; Thulliez, P.; Villena, I.; Aubert, D.; Rabilloud, M.; Riche, B.; et al. Spatial Distribution of Soil Contamination by Toxoplasma gondii in Relation to Cat Defecation Behaviour in an Urban Area. Int. J. Parasitol. 2008, 38, 1017-1023. [CrossRef]

69. Gotteland, C.; Gilot-Fromont, E.; Aubert, D.; Poulle, M.L.; Dupuis, E.; Dardé, M.L.; Forin-Wiart, M.A.; Rabilloud, M.; Riche, B.; Villena, I. Spatial Distribution of Toxoplasma gondii Oocysts in Soil in a Rural Area: Influence of Cats and Land Use. Vet. Parasitol. 2014, 205, 629-637. [CrossRef]

70. Blaizot, R.; Nabet, C.; Laghoe, L.; Faivre, B.; Escotte-Binet, S.; Djossou, F.; Mosnier, E.; Henaff, F.; Blanchet, D.; Mercier, A.; et al. Outbreak of Amazonian Toxoplasmosis: A One Health Investigation in a Remote Amerindian Community. Front. Cell. Infect. Microbiol. 2020, 10, 401. [CrossRef] 
71. Davis, A.A.; Lepczyk, C.A.; Haman, K.H.; Morden, C.W.; Crow, S.E.; Jensen, N.; Lohr, M.T. Toxoplasma gondii Detection in Fecal Samples from Domestic Cats (Felis catus) in Hawaii. Pac. Sci. 2018, 72, 501-511. [CrossRef]

72. Haghparast-Kenari, B.; Sarvi, S.; Sharif, M.; Ahmadpour, E.; Hosseini, S.A.; Daryani, A. Isolation and Genotypic Characterization of Toxoplasma gondii Based on GRA6 Gene from Environmental Soil Samples in Mazandaran Province, North of Iran. Iran. J. Parasitol. 2020, 15, 158-167. [CrossRef] [PubMed]

73. Saki, J.; Khademvatan, S.; Yousefi, E.; Tavalla, M.; Abdizadeh, R. Detection and Genotyping of Toxoplasma gondii Isolated from Soil in Ahvaz, Southwest of Iran. J. Parasit. Dis. 2017, 41, 202-205. [CrossRef] [PubMed]

74. Tavalla, M.; Oormazdi, H.; Akhlaghi, L.; Shojaee, S.; Razmjou, E.; Hadighi, R.; Meamar, A. Genotyping of Toxoplasma gondii Isolates from Soil Samples in Tehran, Iran. Iran. J. Parasitol. 2013, 8, 227-233. [PubMed]

75. Ahmed, D.N.; Muhsin, S.S.; Chyiad, A.L. Comparative Study in Detection of Toxoplasma gondii on Soil Sample from Baghdad and Kut Cities by Using PCR. Indian J. Forensic Med. Toxicol. 2019, 13, 1026. [CrossRef]

76. Pacheco-Ortega, G.A.; Chan-Pérez, J.I.; Ortega-Pacheco, A.; Guzmán-Marín, E.; Edwards, M.; Brown, M.A.; Jiménez-Coello, M.; Hernández-Cortazar, I.B. Screening of Zoonotic Parasites in Playground Sandboxes of Public Parks from Subtropical Mexico. J. Parasitol. Res. 2019, 2019, 7409076. [CrossRef]

77. Frenkel, J.K.; Hassanein, K.M.; Hassanein, R.S.; Brown, E.; Thulliez, P.; Quintero-Nunez, R. Transmission of Toxoplasma gondii in Panama City, Panama: A Five-Year Prospective Cohort Study of Children, Cats, Rodents, Birds, and Soil. Am. J. Trop. Med. Hyg. 1995, 53, 458-468. [CrossRef]

78. Ajmal, A.; Maqbool, A.; Qamar, F.; Ashraf, K.; Anjum, A. Detection of Toxoplasma gondii in Environmental Matrices (Water, Soil, Fruits and Vegetables). Afr. J. Microbiol. Res. 2013, 7, 1505-1511. [CrossRef]

79. Lass, A.; Pietkiewicz, H.; Modzelewska, E.; Dumètre, A.; Szostakowska, B.; Myjak, P. Detection of Toxoplasma gondii Oocysts in Environmental Soil Samples Using Molecular Methods. Eur. J. Clin. Microbiol. Infect. Dis. 2009, 28, 599-605. [CrossRef]

80. Demar, M.; Ajzenberg, D.; Maubon, D.; Djossou, F.; Panchoe, D.; Punwasi, W.; Valery, N.; Peneau, C.; Daigre, J.-L.; Aznar, C.; et al. Fatal Outbreak of Human Toxoplasmosis along the Maroni River: Epidemiological, Clinical, and Parasitological Aspects. Clin. Infect. Dis. 2007, 45, e88-e95. [CrossRef]

81. Deng, H.; Exel, K.E.; Swart, A.; Bonačić Marinović, A.A.; Dam-Deisz, C.; van der Giessen, J.W.B.; Opsteegh, M. Digging into Toxoplasma gondii Infections via Soil: A Quantitative Microbial Risk Assessment Approach. Sci. Total Environ. 2021, 755, 143232. [CrossRef]

82. De Wit, L.A.; Kilpatrick, A.M.; VanWormer, E.; Croll, D.A.; Tershy, B.R.; Kim, M.; Shapiro, K. Seasonal and Spatial Variation in Toxoplasma gondii Contamination in Soil in Urban Public Spaces in California, United States. Zoonoses Public Health 2020, 67, 70-78. [CrossRef] [PubMed]

83. Dubey, J.P.; Weigel, R.M.; Siegel, A.M.; Thulliez, P.; Kitron, U.D.; Mitchell, M.A.; Mannelli, A.; Mateus-Pinilla, N.E.; Shen, S.K.; Kwok, O.C.H.; et al. Sources and Reservoirs of Toxoplasma gondii Infection on 47 Swine Farms in Illinois. J. Parasitol. 1995, 81, 723-729. [CrossRef] [PubMed]

84. Awobode, H.O.; Ohiolei, J.A.; Adekeye, T.A.; Adeyi, A.O.; Anumudu, C.I. Shedding Proportion of Toxoplasma gondii-like Oocysts in Feral Cats and Soil Contamination in Oyo State, Nigeria. Parasite Epidemiol. Control 2020, 11, e00181. [CrossRef] [PubMed]

85. Berrouch, S.; Ajgoune, H.; Hoummadi, L.; Amraouza, Y.; Maarouf, A.; Boularbah, A.; Admou, B.; Hafid, J. First Investigation of The Occurrence of Toxoplasma gondii Oocysts in Urban Soil in Marrakesh, Morocco. Comp. Parasitol. 2020, 87, 99-102. [CrossRef]

86. Do Rego E Silva, G.N.; dos Remédios Freitas Carvalho Branco, M.; Rodrigues, Z.M.R.; dos Santos, A.M.; Pereira, P.R.M.; do Socorro da Silva, M.; de Sousa Nunes, A.T.; Júnior, A.R.J.; Medeiros, M.N.L.; Pedrozo E Silva de Azevedo, C.; et al. Toxoplasmosis Outbreak in Brazil, 2006-Revisited. Parasite Epidemiol. Control 2019, 7, e00117. [CrossRef]

87. Vieira, F.P.; Alves, M.d.G.; Martins, L.M.; Rangel, A.L.P.; Dubey, J.P.; Hill, D.; Bahia-Oliveira, L.M.G. Waterborne Toxoplasmosis Investigated and Analysed under Hydrogeological Assessment: New Data and Perspectives for Further Research. Mem. Inst. Oswaldo Cruz 2015, 110, 929-935. [CrossRef]

88. Da Costa, M.A.; Pinto-Ferreira, F.; de Almeida, R.P.A.; Martins, F.D.C.; Pires, A.L.; Mareze, M.; Mitsuka-Breganó, R.; Freire, R.L.; da Rocha Moreira, R.V.; Borges, J.M.; et al. Artisan Fresh Cheese from Raw Cow's Milk as a Possible Route of Transmission in a Toxoplasmosis Outbreak, in Brazil. Zoonoses Public Health 2020, 67, 122-129. [CrossRef]

89. De Moura, L.; Garcia Bahia-Oliveira, L.M.; Wada, M.Y.; Jones, J.L.; Tuboi, S.H.; Carmo, E.H.; Ramalho, W.M.; Camargo, N.J.; Trevisan, R.; Graça, R.M.T.; et al. Waterborne Toxoplasmosis, Brazil, from Field to Gene. Emerg. Infect. Dis. 2006, 12, 326-329. [CrossRef]

90. Galvani, A.T.; Christ, A.P.G.; Padula, J.A.; Barbosa, M.R.F.; de Araújo, R.S.; Sato, M.I.Z.; Razzolini, M.T.P. Real-Time PCR Detection of Toxoplasma gondii in Surface Water Samples in São Paulo, Brazil. Parasitol. Res. 2019, 118, 631-640. [CrossRef]

91. Isaac-Renton, J.; Bowie, W.R.; King, A.; Irwin, G.S.; Ong, C.S.; Fung, C.P.; Shokeir, M.O.; Dubey, J.P. Detection of Toxoplasma gondii Oocysts in Drinking Water. Appl. Environ. Microbiol. 1998, 64, 2278-2280. [CrossRef]

92. Luna, J.C.; Zamora, A.; Hernández-Arango, N.; Muñoz-Sánchez, D.; Pinzón, M.I.; Cortés-Vecino, J.A.; Lora-Suarez, F.; GómezMarín, J.E. Food Safety Assessment and Risk for Toxoplasmosis in School Restaurants in Armenia, Colombia. Parasitol. Res. 2019, 118, 3449-3457. [CrossRef] [PubMed]

93. Triviño-Valencia, J.; Lora, F.; Zuluaga, J.D.; Gomez-Marin, J.E. Detection by PCR of Pathogenic Protozoa in Raw and Drinkable Water Samples in Colombia. Parasitol. Res. 2016, 115, 1789-1797. [CrossRef] [PubMed] 
94. Slany, M.; Dziedzinska, R.; Babak, V.; Kralik, P.; Moravkova, M.; Slana, I. Toxoplasma gondii in Vegetables from Fields and Farm Storage Facilities in the Czech Republic. FEMS Microbiol. Lett. 2019, 366, fnz170. [CrossRef] [PubMed]

95. El-Tras, W.F.; Tayel, A.A.; El-Kady, N.N. Source Diversity of Toxoplasma gondii Infection during Meal Preparation. J. Food Saf. 2012, 32, 1-5. [CrossRef]

96. Moulin, L.; Richard, F.; Stefania, S.; Goulet, M.; Gosselin, S.; Gonçalves, A.; Rocher, V.; Paffoni, C.; Dumètre, A. Contribution of Treated Wastewater to the Microbiological Quality of Seine River in Paris. Water Res. 2010, 44, 5222-5231. [CrossRef]

97. Villena, I.; Aubert, D.; Gomis, P.; Ferté, H.; Inglard, J.C.; Denis-Bisiaux, H.; Dondon, J.M.; Pisano, E.; Ortis, N.; Pinon, J.M. Evaluation of a Strategy for Toxoplasma gondii Oocyst Detection in Water. Appl. Environ. Microbiol. 2004, 70, 4035-4039. [CrossRef]

98. Aubert, D.; Villena, I. Detection of Toxoplasma gondii Oocysts in Water: Proposition of a Strategy and Evaluation in ChampagneArdenne Region, France. Mem. Inst. Oswaldo Cruz 2009, 104, 290-295. [CrossRef]

99. Ajonina, C.; Buzie, C.; Möller, J.; Otterpohl, R. The Detection of Entamoeba histolytica and Toxoplasma gondii in Wastewater. J. Toxicol. Environ. Health Part A 2018, 81, 1-5. [CrossRef]

100. Gallas-Lindemann, C.; Sotiriadou, I.; Mahmoodi, M.R.; Karanis, P. Detection of Toxoplasma gondii Oocysts in Different Water Resources by Loop Mediated Isothermal Amplification (LAMP). Acta Trop. 2013, 125, 231-236. [CrossRef]

101. Mahmoudi, M.R.; Kazemi, B.; Haghighi, A.; Karanis, P. Detection of Acanthamoeba and Toxoplasma in River Water Samples by Molecular Methods in Iran. Iran. J. Parasitol. 2015, 10, 250-257.

102. Marangi, M.; Giangaspero, A.; Lacasella, V.; Lonigro, A.; Gasser, R.B. Multiplex PCR for the Detection and Quantification of Zoonotic Taxa of Giardia, Cryptosporidium and Toxoplasma in Wastewater and Mussels. Mol. Cell. Probes 2015, 29, 122-125. [CrossRef] [PubMed]

103. Hernandez-Cortazar, I.B.; Acosta-Viana, K.Y.; Guzman-Marin, E.; Ortega-Pacheco, A.; Segura-Correa, J.C.; Jimenez-Coello, M. Presence of Toxoplasma gondii in Drinking Water from an Endemic Region in Southern Mexico. Foodborne Pathog. Dis. 2017, 14, 288-292. [CrossRef]

104. Sroka, J.; Wójcik-Fatla, A.; Dutkiewicz, J. Occurrence of Toxoplasma gondii in Water from Wells Located on Farms. Ann. Agric. Environ. Med. 2006, 13, 169-175. [PubMed]

105. Sroka, J.; Wojcik-Fatla, A.; Szymanska, J.; Dutkiewicz, J.; Zajac, V.; Zwolinski, J. The Occurrence of Toxoplasma gondii Infection in People and Animals from Rural Environment of Lublin Region-Estimate of Potential Role of Water as a Source of Infection. Ann. Agric. Env. Med. 2010, 17, 125-132.

106. Adamska, M. Molecular Detection of Toxoplasma gondii in Natural Surface Water Bodies in Poland. J. Water Health 2018, 16, 657-660. [CrossRef]

107. Sotiriadou, I.; Karanis, P. Evaluation of Loop-Mediated Isothermal Amplification for Detection of Toxoplasma gondii in Water Samples and Comparative Findings by Polymerase Chain Reaction and Immunofluorescence Test (IFT). Diagn. Microbiol. Infect. Dis. 2008, 62, 357-365. [CrossRef]

108. Ssemanda, J.N.; Reij, M.W.; van Middendorp, G.; Bouw, E.; van der Plaats, R.; Franz, E.; Muvunyi, C.M.; Bagabe, M.C.; Zwietering, M.H.; Joosten, H. Foodborne Pathogens and Their Risk Exposure Factors Associated with Farm Vegetables in Rwanda. Food Control 2018, 89, 86-96. [CrossRef]

109. Wells, B.; Shaw, H.; Innocent, G.; Guido, S.; Hotchkiss, E.; Parigi, M.; Opsteegh, M.; Green, J.; Gillespie, S.; Innes, E.A.; et al. Molecular Detection of Toxoplasma gondii in Water Samples from Scotland and a Comparison between the 529bp Real-Time PCR and ITS1 Nested PCR. Water Res. 2015, 87, 175-181. [CrossRef] [PubMed]

110. Ćirković, V.; Uzelac, A.; Milicić, D.; Klun, I.; Đurković-Đaković, O. First Detection of Toxoplasma gondii (Nicolle \& Manceaux, 1908) (Eucoccidiorida: Sarcocystidae) in River Waters in Serbia. Acta Zool. Bulg. 2020, 7, 79-83.

111. Moreno, Y.; Moreno-Mesonero, L.; Amorós, I.; Pérez, R.; Morillo, J.A.; Alonso, J.L. Multiple Identification of Most Important Waterborne Protozoa in Surface Water Used for Irrigation Purposes by 18S RRNA Amplicon-Based Metagenomics. Int. J. Hyg. Environ. Health 2018, 221, 102-111. [CrossRef]

112. Koloren, Z. Sensitive and Cost-Effective Detection of Toxoplasma gondii in Water Supplies of the Black Sea in Turkey by LoopMediated Isothermal Amplification (LAMP). Biotechnol. Biotechnol. Equip. 2013, 27, 3543-3546. [CrossRef]

113. Verant, M.L.; D'Ozouville, N.; Parker, P.G.; Shapiro, K.; Vanwormer, E.; Deem, S.L. Attempted Detection of Toxoplasma gondii Oocysts in Environmental Waters Using a Simple Approach to Evaluate the Potential for Waterborne Transmission in the Galápagos Islands, Ecuador. Ecohealth 2014, 11, 207-214. [CrossRef] [PubMed]

114. Nimir, A.R.; Linn, T.C. Detection of Toxoplasmosis in Environmental Samples at a Wet Market of a Capital City Centre. Acta Med. 2011, 54, 107-110. [CrossRef]

115. Ortiz-Pineda, C.; Guiguet-Leal, D.A.; da Silva-Fiuza, V.R.; Jose, J.; Borelli, G.; Durigan, M.; Pena, H.F.J.; Bueno Franco, R.M. Toxoplasma gondii Oocysts, Giardia Cysts and Cryptosporidium Oocysts in Outdoor Swimming Pools in Brazil. Zoonoses Public Health 2020, 67, 785-795. [CrossRef] [PubMed]

116. Elfadaly, H.A.; Hassanain, N.A.; Hassanain, M.A.; Barakat, A.M.; Shaapan, R.M. Evaluation of Primitive Ground Water Supplies as a Risk Factor for the Development of Major Waterborne Zoonosis in Egyptian Children Living in Rural Areas. J. Infect. Public Health 2018, 11, 203-208. [CrossRef] [PubMed]

117. Shapiro, K.; Silver, M.; Byrne, B.A.; Berardi, T.; Aguilar, B.; Melli, A.; Smith, W.A. Fecal Indicator Bacteria and Zoonotic Pathogens in Marine Snow and California Mussels (Mytilus californianus). FEMS Microbiol. Ecol. 2018, 94, 172. [CrossRef] 
118. Marchioro, A.A.; Tiyo, B.T.; Colli, C.M.; De Souza, C.Z.; Garcia, J.L.; Gomes, M.L.; Falavigna-Guilherme, A.L. First Detection of Toxoplasma gondii DNA in the Fresh Leafs of Vegetables in South America. Vector-Borne Zoonotic Dis. 2016, 16, 624-626. [CrossRef]

119. Ortiz-Pineda, C.; Temesgen, T.T.; Robertson, L.J. Multiplex Quantitative PCR Analysis of Strawberries from Bogotá, Colombia, for Contamination with Three Parasites. J. Food Prot. 2020, 83, 1679-1684. [CrossRef]

120. Caradonna, T.; Marangi, M.; Del Chierico, F.; Ferrari, N.; Reddel, S.; Bracaglia, G.; Normanno, G.; Putignani, L.; Giangaspero, A. Detection and Prevalence of Protozoan Parasites in Ready-to-Eat Packaged Salads on Sale in Italy. Food Microbiol. 2017, 67, 67-75. [CrossRef]

121. Guggisberg, A.R.; Alvarez Rojas, C.A.; Kronenberg, P.A.; Miranda, N.; Deplazes, P. A Sensitive, One-Way Sequential Sieving Method to Isolate Helminths' Eggs and Protozoal Oocysts from Lettuce for Genetic Identification. Pathogens 2020, 9, 624. [CrossRef]

122. Al-Megrin, W.A.I. Prevalence Intestinal Parasites in Leafy Vegetables in Riyadh, Saudi Arabia. Int. J. Trop. Med. 2010, 5, 20-23. [CrossRef]

123. Haq, S.; Maqbool, A.; Javed Khan, U.; Yasmin, G.; Sultana, R. Parasitic Contamination of Vegetables Eaten Raw in Lahore. Pak. J. Zool. 2014, 46, 1303-1309.

124. Medeiros, F.A.; de Oliveira, T.R.; Málaga, S.M.R. Segurança Dos Alimentos: Influência Sazonal Na Contaminação Parasitária Em Alface (Lactuca sativa L.) Comercializada Em Feiras Livres de Belém, Pará. Braz. J. Food Technol. 2019, 22. [CrossRef]

125. Mohammed, R.G.; Kadhim, H.A.H.; Ali, J.F. Diagnostic Study on Intestinal Parasites Isolated from Raw Consumed Vegetables in Misan City/Iraq. Indian J. Public Health Res. Dev. 2019, 10, 1236-1240. [CrossRef]

126. M'Rad, S.; Chaabane-Banaoues, R.; Lahmar, I.; Oumaima, H.; Mezhoud, H.; Babba, H.; Oudni-M'Rad, M. Parasitological Contamination of Vegetables Sold in Tunisian Retail Markets with Helminth Eggs and Protozoan Cysts. J. Food Prot. 2020, 83, 1104-1109. [CrossRef]

127. Dardona, Z.; Al Hindi, A.; Hafidi, M.; Boumezzough, A.; Boussaa, S. Occurrence of Toxoplasma gondii on Raw Leafy Vegetables in Gaza, Palestine. J. Food Prot. 2021, 84, 255-261. [CrossRef]

128. Khalil, H.I. Prevalence of Enteric Parasites in Raw Leafy Vegetables in Baghdad City, Iraq. Indian J. Public Health Res. Dev. 2019, 10, 446-450. [CrossRef]

129. Ahmad, S.O.; El Fadaly, A.H.; Zaki, M.S.; Barakat, A.M. Incidence of Zoonotic Parasites In Egyptian Raw Vegetable Salads. Life Sci. J. 2016, 13, 27-31. [CrossRef]

130. Esmerini, P.O.; Gennari, S.M.; Pena, H.F.J. Analysis of Marine Bivalve Shellfish from the Fish Market in Santos City, São Paulo State, Brazil, for Toxoplasma gondii. Vet. Parasitol. 2010, 170, 8-13. [CrossRef]

131. Ribeiro, L.A.; Santos, L.K.N.S.S.; Brito, P.A.; Maciel, B.M.; Da Silva, A.V.; Albuquerque, G.R. Detection of Toxoplasma gondii DNA in Brazilian Oysters (Crassostrea rhizophorae). Genet. Mol. Res. 2015, 14, 4658-4665. [CrossRef]

132. Monteiro, T.R.M.; Rocha, K.S.; Silva, J.; Mesquita, G.S.S.; Rosário, M.K.S.; Ferreira, M.F.S.; Honorio, B.E.T.; Melo, H.F.R.; Barros, F.N.L.; Scofield, A.; et al. Detection of Toxoplasma gondii in Crassostrea spp. Oysters Cultured in an Estuarine Region in Eastern Amazon. Zoonoses Public Health 2019, 66, 296-300. [CrossRef]

133. Cong, W.; Zhang, N.Z.; Hou, J.L.; Wang, X.C.; Ma, J.G.; Zhu, X.Q.; Chen, G.J. First Detection and Genetic Characterization of Toxoplasma gondii in Market-Sold Oysters in China. Infect. Genet. Evol. 2017, 54, 276-278. [CrossRef]

134. Cong, W.; Zhang, N.Z.; Yuan, D.Q.; Zou, Y.; Li, S.; Liang, Z.L. Detection and Genetic Characterization of Toxoplasma gondii in Market-Sold Mussels (Mytilus edulis) in Certain Provinces of China. Microb. Pathog. 2019, 136, 103687. [CrossRef]

135. Zhang, M.; Yang, Z.; Wang, S.; Tao, L.F.; Xu, L.X.; Yan, R.F.; Song, X.K.; Li, X.R. Detection of Toxoplasma gondii in Shellfish and Fish in Parts of China. Vet. Parasitol. 2014, 200, 85-89. [CrossRef]

136. Kerambrun, E.; Palos Ladeiro, M.; Bigot-Clivot, A.; Dedourge-Geffard, O.; Dupuis, E.; Villena, I.; Aubert, D.; Geffard, A. Zebra Mussel as a New Tool to Show Evidence of Freshwater Contamination by Waterborne Toxoplasma gondii. J. Appl. Microbiol. 2016, 120, 498-508. [CrossRef]

137. Santoro, M.; Viscardi, M.; Boccia, F.; Borriello, G.; Lucibelli, M.G.; Auriemma, C.; Anastasio, A.; Veneziano, V.; Galiero, G.; Baldi, L.; et al. Parasite Load and STRs Genotyping of Toxoplasma gondii Isolates From Mediterranean Mussels (Mytilus galloprovincialis) in Southern Italy. Front. Microbiol. 2020, 11, 355. [CrossRef]

138. Tedde, T.; Marangi, M.; Papini, R.; Salza, S.; Normanno, G.; Virgilio, S.; Giangaspero, A. Toxoplasma gondii and Other Zoonotic Protozoans in Mediterranean Mussel (Mytilus galloprovincialis) and Blue Mussel (Mytilus edulis): A Food Safety Concern? J. Food Prot. 2019, 82, 535-542. [CrossRef]

139. Putignani, L.; Mancinelli, L.; Del Chierico, F.; Menichella, D.; Adlerstein, D.; Angelici, M.C.; Marangi, M.; Berrilli, F.; Caffara, M.; di Regalbono, D.A.F.; et al. Investigation of Toxoplasma gondii Presence in Farmed Shellfish by Nested-PCR and Real-Time PCR Fluorescent Amplicon Generation Assay (FLAG). Exp. Parasitol. 2011, 127, 409-417. [CrossRef]

140. Ghozzi, K.; Marangi, M.; Papini, R.; Lahmar, I.; Challouf, R.; Houas, N.; Ben Dhiab, R.; Normanno, G.; Babba, H.; Giangaspero, A. First Report of Tunisian Coastal Water Contamination by Protozoan Parasites Using Mollusk Bivalves as Biological Indicators. Mar. Pollut. Bull. 2017, 117, 197-202. [CrossRef] [PubMed]

141. Aksoy, U.; Marangi, M.; Papini, R.; Ozkoc, S.; Bayram Delibas, S.; Giangaspero, A. Detection of Toxoplasma gondii and Cyclospora cayetanensis in Mytilus galloprovincialis from Izmir Province Coast (Turkey) by Real Time PCR/High-Resolution Melting Analysis (HRM). Food Microbiol. 2014, 44, 128-135. [CrossRef] [PubMed] 
142. Tei, F.; Kowalyk, S.; Reid, J.; Presta, M.; Yesudas, R.; Mayer, D.C. Assessment and Molecular Characterization of Human Intestinal Parasites in Bivalves from Orchard Beach, NY, USA. Int. J. Environ. Res. Public Health 2016, 13, 381. [CrossRef] [PubMed]

143. Dubey, J.P. Outbreaks of Clinical Toxoplasmosis in Humans: Five Decades of Personal Experience, Perspectives and Lessons Learned. Parasites Vectors 2021, 14, 263. [CrossRef]

144. Efstratiou, A.; Ongerth, J.; Karanis, P. Evolution of Monitoring for Giardia and Cryptosporidium in Water. Water Res. 2017, 123, 96-112. [CrossRef] [PubMed]

145. Javanmard, E.; Mirsamadi, E.S.; Olfatifar, M.; Ghasemi, E.; Saki, F.; Mirjalali, H.; Zali, M.R.; Karanis, P. Prevalence of Cryptosporidium and Giardia in Vegetables in Iran: A Nineteen-Years Meta-Analysis Review. J. Environ. Health Sci. Eng. 2020, 18, $1629-1641$. [CrossRef] [PubMed]

146. Lélu, M.; Villena, I.; Dardé, M.L.; Aubert, D.; Geers, R.; Dupuis, E.; Marnef, F.; Poulle, M.L.; Gotteland, C.; Dumètre, A.; et al. Quantitative Estimation of the Viability of Toxoplasma gondii Oocysts in Soil. Appl. Environ. Microbiol. 2012, 78, 5127-5132. [CrossRef] [PubMed]

147. Lélu, M.; Gilot-Fromont, E.; Aubert, D.; Richaume, A.; Afonso, E.; Dupuis, E.; Gotteland, C.; Marnef, F.; Poulle, M.L.; Dumètre, A.; et al. Development of a Sensitive Method for Toxoplasma gondii Oocyst Extraction in Soil. Vet. Parasitol. 2011, 183, 59-67. [CrossRef] [PubMed]

148. Zilberman, A.; Zimmels, Y.; Starosvetsky, J.; Zuckerman, U.; Armon, R. A Two-Phase Separation Method for Recovery of Cryptosporidium Oocysts from Soil Samples. Water Air Soil Pollut. 2009, 203, 325-334. [CrossRef]

149. Bradford, S.A.; Bettahar, M. Straining, Attachment, and Detachment of Cryptosporidium Oocysts in Saturated Porous Media. J. Environ. Qual. 2005, 34, 469-478. [CrossRef]

150. Dubey, J.P. Toxoplasma gondii Oocyst Survival under Defined Temperatures. J. Parasitol. 1998, 84, 862-865. [CrossRef] [PubMed]

151. Jones, J.L.; Dubey, J.P. Waterborne Toxoplasmosis-Recent Developments. Exp. Parasitol. 2010, 124, 10-25. [CrossRef]

152. Young, I.; Smith, B.A.; Fazil, A. A Systematic Review and Meta-Analysis of the Effects of Extreme Weather Events and Other Weather-Related Variables on Cryptosporidium and Giardia in Fresh Surface Waters. J. Water Health 2015, 13, 1-17. [CrossRef] [PubMed]

153. Barlaam, A.; Temesgen, T.T.; Tysnes, K.R.; Rinaldi, L.; Ferrari, N.; Sannella, A.R.; Normanno, G.; Cacciò, S.M.; Robertson, L.J.; Giangaspero, A. Contamination of Fresh Produce Sold on the Italian Market with Cyclospora cayetanensis and Echinococcus multilocularis. Food Microbiol. 2021, 98, 103792. [CrossRef]

154. Lilly, E.L.; Webster, N.J. Detection of Toxoplasma gondii Oocysts on Organic and Conventionally Grown Produce. Food Microbiol. 2021, 99, 103798. [CrossRef] [PubMed]

155. EFSA. Scientific Opinion on the Risk Posed by Pathogens in Food of Non-animal Origin. Part 2 (Salmonella and Norovirus in Leafy Greens Eaten Raw as Salads). EFSA J. 2014, 12, 3600. [CrossRef]

156. Chaidez, C.; Soto, M.; Gortares, P.; Mena, K. Occurrence of Cryptosporidium and Giardia in Irrigation Water and Its Impact on the Fresh Produce Industry. Int. J. Environ. Health Res. 2005, 15, 339-345. [CrossRef] [PubMed]

157. Arkush, K.D.; Miller, M.A.; Leutenegger, C.M.; Gardner, I.A.; Packham, A.E.; Heckeroth, A.R.; Tenter, A.M.; Barr, B.C.; Conrad, P.A. Molecular and Bioassay-Based Detection of Toxoplasma gondii Oocyst Uptake by Mussels (Mytilus galloprovincialis). Int. J. Parasitol. 2003, 33, 1087-1097. [CrossRef]

158. Palos-Ladeiro, M.; Bigot-Clivot, A.; Aubert, D.; Villena, I.; Geffard, A. Assessment of Toxoplasma gondii Levels in Zebra Mussel (Dreissena polymorpha) by Real-Time PCR: An Organotropism Study. Environ. Sci. Pollut. Res. 2015, 22, 13693-13701. [CrossRef] [PubMed]

159. Jones, J.L.; Dargelas, V.; Roberts, J.; Press, C.; Remington, J.S.; Montoya, J.G. Risk Factors for Toxoplasma gondii Infection in the United States. Clin. Infect. Dis. 2009, 49, 878-884. [CrossRef] [PubMed]

160. Fritz, H.; Conrad, P. Antibodies to the Surface of Toxoplasma gondii Oocysts and Methods of Use Thereof. U.S. Patent 10429386B2, 18 January 2018.

161. Sousa, S.; Almeida, A.; Delgado, L.; Conceição, A.; Marques, C.; da Costa, J.M.C.; Castro, A. RTgOWP1-f, a Specific Biomarker for Toxoplasma gondii Oocysts. Sci. Rep. 2020, 10, 1-8. [CrossRef] [PubMed]

162. Dumètre, A.; Dardé, M.L. Immunomagnetic Separation of Toxoplasma gondii Oocysts Using a Monoclonal Antibody Directed against the Oocyst Wall. J. Microbiol. Methods 2005, 61, 209-217. [CrossRef]

163. Dumètre, A.; Dardé, M.-L. Detection of Toxoplasma gondii in Water by an Immunomagnetic Separation Method Targeting the Sporocysts. Parasitol. Res. 2007, 101, 989-996. [CrossRef] [PubMed]

164. Harito, J.B.; Campbell, A.T.; Tysnes, K.R.; Robertson, L.J. Use of Lectin-Magnetic Separation (LMS) for Detecting Toxoplasma gondii Oocysts in Environmental Water Samples. Water Res. 2017, 127, 68-76. [CrossRef] [PubMed]

165. Chalmers, R.M.; Katzer, F.; La Carbona, S.; Lalle, M.; Razakandrainibe, R.; Robertson, L.J.; Robinson, G.; Šoba, B.; Temesgen, T.; Mayer-Scholl, A. A Guide to Standardise Artificial Contamination Procedures with Protozoan Parasite Oocysts or Cysts during Method Evaluation, Using Cryptosporidium and Leafy Greens as Models. Food Control 2022, 134, 108678. [CrossRef]

166. Schares, G.; Globokar Vrhovec, M.; Tuschy, M.; Joeres, M.; Bärwald, A.; Koudela, B.; Dubey, J.P.; Maksimov, P.; Conraths, F.J. A Real-Time Quantitative Polymerase Chain Reaction for the Specific Detection of Hammondia hammondi and Its Differentiation from Toxoplasma gondii. Parasit. Vectors 2021, 14, 78. [CrossRef] [PubMed]

167. Coupe, A.; Howe, L.; Shapiro, K.; Roe, W.D. Comparison of PCR Assays to Detect Toxoplasma gondii Oocysts in Green-Lipped Mussels (Perna canaliculus). Parasitol. Res. 2019, 118, 2389-2398. [CrossRef] 
168. Grigg, M.E.; Boothroyd, J.C. Rapid Identification of Virulent Type I Strains of the Protozoan Pathogen Toxoplasma gondii by PCR-Restriction Fragment Length Polymorphism Analysis at the B1 Gene. J. Clin. Microbiol. 2001, 39, 398-400. [CrossRef]

169. Su, C.; Shwab, E.K.; Zhou, P.; Zhu, X.Q.; Dubey, J.P. Moving towards an Integrated Approach to Molecular Detection and Identification of Toxoplasma gondii. Parasitology 2010, 137, 1-11. [CrossRef]

170. Ajzenberg, D.; Collinet, F.; Mercier, A.; Vignoles, P.; Dardé, M.-L. Genotyping of Toxoplasma gondii Isolates with 15 Microsatellite Markers in a Single Multiplex PCR Assay. J. Clin. Microbiol. 2010, 48, 4641-4645. [CrossRef] [PubMed]

171. Jokelainen, P.; Murat, J.-B.; Nielsen, H.V. Direct Genetic Characterization of Toxoplasma gondii from Clinical Samples from Denmark: Not Only Genotypes II and III. Eur. J. Clin. Microbiol. Infect. Dis. 2018, 37, 579-586. [CrossRef]

172. Fernández-Escobar, M.; Maksimov, P.; Joeres, M.; Álvarez-García, G.; Jokelainen, P.; Schares, G.; Ortega-Mora, L.M.; Calero-Bernal, R. Lights and Shades in Genotyping: European Toxoplasma gondii Needs a Closer Look Using Harmonised Approaches. In Proceedings of the Annual Scientific 2021, Copenhagen, Denmark, 9-11 June 2021.

173. Dubey, J.P. Toxoplasmosis of Animals and Humans, 3rd ed.; CRC Press: Boca Raton, FL, USA, 2021.

174. Ware, M.W.; Augustine, S.A.J.; Erisman, D.O.; See, M.J.; Wymer, L.; Hayes, S.L.; Dubey, J.P.; Villegas, E.N. Determining UV Inactivation of Toxoplasma gondii Oocysts by Using Cell Culture and a Mouse Bioassay. Appl. Environ. Microbiol. 2010, 76, 5140-5147. [CrossRef]

175. Rousseau, A.; La Carbona, S.; Dumètre, A.; Robertson, L.J.; Gargala, G.; Escotte-Binet, S.; Favennec, L.; Villena, I.; Gérard, C.; Aubert, D. Assessing Viability and Infectivity of Foodborne and Waterborne Stages (Cysts/Oocysts) of Giardia Duodenalis, Cryptosporidium spp., and Toxoplasma gondii: A Review of Methods. Parasite 2018, 25, 14. [CrossRef]

176. Dubey, J.P. Toxoplasmosis in Pigs-The Last 20 Years. Vet. Parasitol. 2009, 164, 89-103. [CrossRef]

177. Dong, H.; Su, R.; Lu, Y.; Wang, M.; Liu, J.; Jian, F.; Yang, Y. Prevalence, Risk Factors, and Genotypes of Toxoplasma gondii in Food Animals and Humans (2000-2017) from China. Front. Microbiol. 2018, 9, 2108. [CrossRef]

178. Olsen, A.; Berg, R.; Tagel, M.; Must, K.; Deksne, G.; Enemark, H.L.; Alban, L.; Johansen, M.V.; Nielsen, H.V.; Sandberg, M.; et al. Seroprevalence of Toxoplasma gondii in Domestic Pigs, Sheep, Cattle, Wild Boars, and Moose in the Nordic-Baltic Region: A Systematic Review and Meta-Analysis. Parasite Epidemiol. Control 2019, 5, e00100. [CrossRef]

179. Maldonade, I.R.; Ginani, V.C.; Riquette, R.F.R.; Gurgel-Gonçalves, R.; Mendes, V.S.; Machado, E.R. Good Manufacturing Practices of Minimally Processed Vegetables Reduce Contamination with Pathogenic Microorganisms. Rev. Inst. Med. Trop. 2019, 61. [CrossRef]

180. Meireles, L.R.; Ekman, C.C.J.; de Andrade, H.F.; Luna, E.J.d.A. Human toxoplasmosis outbreaks and the agent infecting form. Findings from a systematic review. Rev. Inst. Med. Trop. 2015, 57, 369. [CrossRef]

181. Thebault, A.; Kooh, P.; Cadavez, V.; Gonzales-Barron, U.; Villena, I. Risk Factors for Sporadic Toxoplasmosis: A Systematic Review and Meta-Analysis. Microb. Risk Anal. 2021, 17, 100133. [CrossRef]

182. Rostami, A.; Riahi, S.M.; Esfandyari, S.; Habibpour, H.; Mollalo, A.; Mirzapour, A.; Behniafar, H.; Mohammadi Moghadam, S.; Azizi Kyvanani, N.; Aghaei, S.; et al. Geo-Climatic Factors and Prevalence of Chronic Toxoplasmosis in Pregnant Women: A Meta-Analysis and Meta-Regression. Environ. Pollut. 2021, 288, 117790. [CrossRef] 